\title{
Clustering of adult-onset diabetes into novel subgroups guides therapy and improves prediction of outcome
}

\author{
Authors: E Ahlqvist ${ }^{1} \mathrm{PhD}, \mathrm{P}$ Storm ${ }^{1} \mathrm{PhD}, \mathrm{A}$ Käräjämäki ${ }^{2 \dagger} \mathrm{MD}, \mathrm{M}$ Martinell ${ }^{3 \dagger} \mathrm{MD}$, M Dorkhan ${ }^{1}$ \\ PhD, A Carlsson ${ }^{4} \mathrm{PhD}, \mathrm{P}$ Vikman ${ }^{1} \mathrm{PhD}, \mathrm{RB} \operatorname{Prasad}^{1} \mathrm{PhD}$, D Mansour Aly ${ }^{1}$ MSc, P Almgren ${ }^{1}$ \\ MSc, Y Wessman ${ }^{1}$, N Shaat ${ }^{1} \mathrm{PhD}, \mathrm{P}_{\text {Spegel }^{1,5}} \mathrm{PhD}^{\mathrm{H}}$ H Mulder ${ }^{1} \mathrm{PhD}, \mathrm{E}$ Lindholm $^{1} \mathrm{PhD}, \mathrm{O}$ \\ Melander ${ }^{1} \mathrm{PhD}, \mathrm{O}$ Hansson ${ }^{1} \mathrm{PhD}, \mathrm{U}$ Malmqvist ${ }^{6} \mathrm{PhD}, \AA$ Lernmark $^{1} \mathrm{PhD}, \mathrm{K}$ Lahti $^{2} \mathrm{MD}, \mathrm{T}$ \\ Forsén $^{7} \mathrm{PhD}, \mathrm{T}$ Tuomi ${ }^{7,8,9} \mathrm{PhD}, \mathrm{AH}$ Rosengren ${ }^{1} \mathrm{PhD}, \mathrm{L} \mathrm{Groop}^{1,7^{*}} \mathrm{PhD}$.
}

\section{Affiliations:}

${ }^{1 *}$ Lund University Diabetes Centre, Department of Clinical Sciences, Lund University, Skåne University Hospital, SE-20502 Malmö, Sweden.

${ }^{2}$ Department of Primary Health Care, Vaasa Central Hospital, Hietalahdenkatu 2-4, 65130 Vaasa, Finland \& Diabetes Center, Vaasa Health Care Center, Sepänkyläntie 14-16, 65100 Vaasa, Finland.

${ }^{3}$ Department of Public Health and Caring Sciences, Uppsala University, Uppsala, Sweden.

${ }^{4}$ Lund University Diabetes Centre, Department of Clinical Sciences, Lund University, Skåne University Hospital, SE-22185 Lund, Sweden.

${ }^{5}$ Department of Chemistry, Centre for Analysis and Synthesis, Lund University, Lund, Sweden

${ }^{6}$ Clinical Research and Trial Center, Lund University Hospital, Sweden.

${ }^{7}$ Folkhälsan Research Center, Helsinki, Finland.

${ }^{8}$ Abdominal Center, Endocrinology, Helsinki University Central Hospital; Research Program for Diabetes and Obesity, University of Helsinki, Helsinki, Finland.

${ }^{9}$ Finnish Institute for Molecular Medicine (FIMM), Helsinki University, Helsinki, Finland.

*Equal contribution

**Correspondence to: Professor Leif Groop, leif.groop@med.lu.se, phone +46-40-391202. 


\section{Research in context}

\section{Evidence before this study}

The current diabetes classification into T1D and T2D relies primarily on presence (T1D) or absence (T2D) of autoantibodies against pancreatic islet beta cell autoantigens and age at diagnosis (earlier for T1D). With this approach 75-85\% of patients are classified as T2D. A third subgroup, Latent Autoimmune Diabetes in Adults (LADA, $<10 \%$ ), is defined by presence of autoantibodies against glutamate decarboxylase (GADA) with onset in adult age. In addition, several rare monogenic forms of diabetes have been described, including Maturity Onset Diabetes of the Young (MODY) and neonatal diabetes. This information is provided by national guidelines (ADA,WHO, IDF, Diabetes UK etc) but has not been much updated during the past 20 years and very few attempts have been made to explore heterogeneity of T2D. A topological analysis of potential T2D subgroups using electronic health records was published in 2015 but this information has not been implemented in the clinic.

\section{Added value of this study}

Here we applied a data-driven cluster analysis of 5 simple variables measured at diagnosis in 4 independent cohorts of newly-diagnosed diabetic patients $(\mathrm{N}=14755)$ and identified 5 replicable clusters of diabetes patients, with significantly different patient characteristics and risk of diabetic complications. Particularly, individuals in the most insulin-resistant cluster 3 had significantly higher risk of diabetic kidney disease.

\section{Implications of the available evidence}

This new sub-stratification may help to tailor and target early treatment to patients who would benefit most, thereby representing a first step towards precision medicine in diabetes 


\section{Abstract}

\section{Background}

Diabetes is presently classified into two main forms, type 1 (T1D) and type 2 diabetes (T2D), but especially T2D is highly heterogeneous. A refined classification could provide a powerful tool individualize treatment regimes and identify individuals with increased risk of complications already at diagnosis.

\section{Methods}

We applied data-driven cluster analysis (k-means and hierarchical clustering) in newly diagnosed diabetic patients $(\mathrm{N}=8,980)$ from the Swedish ANDIS (All New Diabetics in Scania) cohort, using five variables (GAD-antibodies, BMI, HbA1c, HOMA2-B and HOMA2-IR), and related to prospective data on development of complications and prescription of medication from patient records. Replication was performed in three independent cohorts: the Scania Diabetes Registry (SDR, N=1466), ANDIU (All New Diabetics in Uppsala, N=844) and DIREVA (Diabetes Registry Vaasa, $\mathrm{N}=3485$ ). Cox regression and logistic regression was used to compare time to medication, time to reaching the treatment goal and risk of diabetic complications and genetic associations.

\section{Findings}

We identified 5 replicable clusters of diabetes patients, with significantly different patient characteristics and risk of diabetic complications. Particularly, individuals in the most insulinresistant cluster 3 had significantly higher risk of diabetic kidney disease, but had been prescribed similar diabetes treatment compared to the less susceptible individuals in clusters 4 and 5 . The 
insulin deficient cluster 2 had the highest risk of retinopathy. In support of the clustering, genetic associations to the clusters differed from those seen in traditional T2D.

\section{Interpretation}

We could stratify patients into five subgroups predicting disease progression and development of diabetic complications more precisely than the current classification. This new substratificationn may help to tailor and target early treatment to patients who would benefit most, thereby representing a first step towards precision medicine in diabetes.

\section{Funding}

The funders of the study had no role in study design, data collection, analysis, interpretation or writing of the report. 


\section{Introduction}

Diabetes is the fastest increasing disease worldwide and one of the greatest threats to human health. ${ }^{1}$ Unfortunately, current treatment strategies have not been able to stop the progressive course of the disease and prevent development of chronic diabetic complications. There are several explanations for these shortcomings. Diagnosis of diabetes is based upon measurement of only one metabolite, glucose, but the disease is very heterogeneous with regard to clinical presentation and progression.

The current diabetes classification into T1D and T2D relies primarily on presence (T1D) or absence (T2D) of autoantibodies against pancreatic islet beta cell autoantigens and age at diagnosis (earlier for T1D). With this approach $75-85 \%$ of patients are classified as T2D. A third subgroup, Latent Autoimmune Diabetes in Adults (LADA, $<10 \%$ ), defined by presence of autoantibodies against glutamate decarboxylase (GADA) is phenotypically indistinguishable from T2D at diagnosis but become more T1D-like with time. ${ }^{2}$ With the introduction of gene sequencing for clinical diagnostics several rare monogenic forms of diabetes were described, including Maturity Onset Diabetes of the Young (MODY) and neonatal diabetes. ${ }^{3,4}$

A limitation to current treatment guidelines is that they respond to poor metabolic control when it has developed but lack means to predict which patients will need intensified treatment. Importantly, accumulating evidence suggests that the early treatment is critical for prevention of life-shortening complications since target tissues seem to remember poor metabolic control decades later, also referred to as "metabolic memory". 5, 6

A refined classification could provide a powerful tool to identify those at greatest risk of complications already at diagnosis, and enable individualized treatment regimes in the same way as a genetic diagnosis of monogenic forms of diabetes guides clinicians to optimal treatment. ${ }^{7}$ 
With this aim, we present a novel diabetes classification based on unsupervised data-driven cluster analysis of six commonly measured variables and compare it metabolically, genetically and clinically to the current classification in four separate populations from Sweden and Finland.

\section{Methods}

\section{Study populations}

The ANDIS (All New Diabetics in Scania) project (http://andis.ludc.med.lu.se/) aims to recruit all incident cases of diabetes within Scania (Skåne) County in southern Sweden, which has about 1,200,000 inhabitants. All health care providers in the region were invited; the current registration covered the period January $1^{\text {st }} 2008$ until November 2016 during which 177 clinics registered 14,625 patients (> 90\% of eligible patients), aged 0-96 years within a median of 40 days (IQR 12-99) after diagnosis.

The Scania Diabetes Registry (SDR) was recruited in the same region of Sweden between 1996 and 2009 including > 7,400 individuals with diabetes of all types, 1,466 of whom were recruited no longer than two years after diagnosis and had all data necessary for clustering. ${ }^{8}$

ANDIU (All new diabetics in Uppsala) is a project similar to ANDIS started in 2011. Subjects are recruited in the Uppsala region ( 300,000 inhabitants) in Sweden (http://www.andiu.se). $\mathrm{N}=844$ patients had complete data for all clustering variables.

DIREVA (Diabetes Registry Vaasa) from Western Finland ( 170,000 inhabitants) includes 5107 individuals with diabetes recruited 2009-2014. 
MDC-CVA (Malmö Diet and Cancer) includes subjects living in Malmö, Southern Sweden who were invited to a clinical examination, including oral glucose tolerance tests to diagnose diabetes $(n=3,300) .{ }^{9}$ Individuals without diabetes were used as controls for the genetic analyses.

\section{Measurements}

In ANDIS blood samples were drawn at the registration visit for measurements of glucose, Cpeptide, GAD autoantibodies, metabolites and DNA. Fasting plasma glucose was analyzed after an overnight fast using the HemoCue Glucose System (HemoCue AB, Ängelholm, Sweden). Cpeptide concentrations were determined using an ElectroChemiLuminiscenceImmunoassay on Cobas e411 (Roche Diagnostics, Mannheim, Germany) or by. radioimmunoassay (Human Cpeptide RIA; Linco, St Charles, MO, USA; or Peninsula Laboratories, Belmont, CA, USA). In ANDIS and SDR GADA was measured by an Enzyme-Linked Immunosorbent Assay (ELISA) (ref $<11 \mathrm{U} / \mathrm{ml}^{10}$ ) or with radiobinding assays using $35 \mathrm{~S}$-labelled protein ${ }^{11}$ (positive cut-off: $5 \mathrm{RU}$ or $32 \mathrm{IU} / \mathrm{ml})$. The radiobinding assay showed $62-88 \%$ sensitivity and $91-99 \%$ specificity in workshops (Combinatorial Autoantibody or Diabetes/Islet Autoantibody Standardization Programs) from 1998 to 2013, and the ELISA assay showed 72\% sensitivity and 99\% specificity in the 2013 Islet Autoantibody Standardization Program workshop. In ANDIU GADA was measured at Laboratory Medicine in Uppsala (ref $<5 \mathrm{U} / \mathrm{ml}$ ). In DIREVA, GADA were measured with an ELISA assay (RSR, Cardiff, UK; positive cut-off $10 \mathrm{IU} / \mathrm{ml}$ ). ZnT8A antibodies were measured using a Radio-Binding Assay as previously described. ${ }^{12}$ HbAlc was measured at diagnosis by the treating physician. HOMA2B and HOMA2IR were calculated from fasting Cpeptide and glucose using the HOMA calculator (the University of Oxford, UK). ${ }^{13}$ Measurements of HbA1c, ALT, ketones and serum creatinine over time were obtained from the Clinical Chemistry department database. 


\section{Genotyping}

Genotyping was carried out using iPlex (Sequenom, San Diego, California, US) or TaqMan assays (Thermo Fisher Scientific). Patients and SNPs with call rate $<90 \%$ were excluded.

\section{Definitions of diabetic complications}

The MDRD (Modification of Diet in Renal Disease) formula ${ }^{14}$ was used to calculate estimated glomerular filtration rate (eGFR). Chronic kidney disease (CKD) was defined as eGFR <60 (CKD stage 3A) or $<45$ (CKD stage 3B) for more than 90 days (onset of CKD was set as the start of the $>90$ day period). End-stage renal disease (ESRD) was defined as at least one eGFR below 15 $\mathrm{mL} / \mathrm{min} / 1 \cdot 73 \mathrm{~m} 2$.

Macroalbuminuria was defined as at least two out of three consecutive visits with albumin excretion rate $(\mathrm{AER}) \geq 200 \mu \mathrm{g} / \mathrm{min}$ or $\mathrm{AER} \geq 300 \mathrm{mg} / 24 \mathrm{~h}$ or albumin-creatinine ratio (ACR) $\geq 25 / 35 \mathrm{mg} / \mathrm{mmol}$ for men/women.

Diabetic retinopathy was diagnosed by an ophthalmologist based on fundus photographs. ${ }^{15}$ Coronary events (CE) were defined by ICD-10 codes I21, I252, I20, I251, I253, I254, I255, I256, I257, I258 and I259. Stroke was defined by ICD-10 codes I60, I61, I63 and I64.

\section{Cluster analysis}

Cluster analysis was performed on scaled and centered values. Patients with secondary diabetes were excluded, as were extreme outliers (>5 SD). GADA was included as a dichotomous variable. TwoStep clustering was performed in SPSS v.23 for 2 to 15 clusters using loglikelihood as distance measure and Schwarz's Bayesian criterion for clustering. K-means clustering was performed with $\mathrm{k}=4$ using the kmeansruns function (runs=100) in the fpc package in R. Cluster centres in ANDIS used to classify patients in replication cohorts are presented in 
table s3. Assessment of clusterwise stability was carried out by resampling the dataset 2,000 times and computing the Jaccard similarities to the original cluster. Generally, a stable cluster should yield a Jaccard similarity $>0 \cdot 75 .^{16}$

\section{Statistical analysis}

Risk of complications was calculated using cox regression in SPSS v.23. Sex was included as a covariate in all analyses. Analysis including sex and age at onset of diabetes or first eGFR was also performed as indicated in the text.

Associations between clusters and genotypes were calculated using the MLE method in SNPtest2. The equality of odds ratios across strata in table1 was tested using seemingly unrelated estimation (suest) as implemented in Stata. Non-diabetic individuals from the MDC-CVA cohort were used as controls. Patients of known non-Swedish origin were excluded.

\section{Funding}

The funding agencies had no role in study design, data collection, data analysis, data interpretation, or writing of the report.

\section{Results}

We first analyzed a cohort of 14,652 newly diagnosed diabetic patients from Sweden termed ANDIS (All New Diabetics in Scania). Of them, 932 (6.4\%) were registered before age 18 and not included in analyses of adult diabetes. Of the adult patients, $1.4 \%$ had T1D (defined as GADA positive and C-peptide $<0.3 \mathrm{nmol} / \mathrm{l}$ ), 4.9\% LADA (GADA-positive and C-peptide $\geq 0.3$ 
nmol/l), $1 \cdot 1 \%$ secondary diabetes (coexisting pancreatic disease) and $3 \cdot 5 \%$ were unclassifiable due to missing data. The remaining patients $(82 \cdot 7 \%)$ were considered to have T2D (Table S1).

Five quantitative variables (age, BMI, HbA1c, Homeostasis Model Assessment 2 estimates of beta-cell function [HOMA2-B] and insulin resistance [HOMA2-IR]), plus presence or absence of GADA as a binary variable, were used in a cluster analysis to reclassify patients into novel diabetes subgroups. Fasting C-peptide and plasma glucose were used to estimate HOMA2. ${ }^{13}$ Patients with complete data for the clustering variables $(\mathrm{N}=8,980)$ were included in the further analyses (Figure 1A, Table S1).

First, we applied TwoStep clustering; the first step estimates the optimal number of clusters based upon silhouette width and the second step performs hierarchical clustering. Men $(\mathrm{N}=5,334)$ and women $(\mathrm{N}=3,646)$ were clustered separately; patients with secondary diabetes were excluded from subsequent analyses. The minimum silhouette width was found for 5 clusters in both men and women, exhibiting similar cluster distributions and characteristics (Figure S1). We verified the results using a second clustering method, k-means clustering. Because all GADA-positive patients clustered together in TwoStep analysis, and k-means clustering is inappropriate for binary variables, we restricted the k-means clustering to GADA-negative patients. This resulted in a similar cluster distribution as TwoStep with the same overall cluster characteristics in both sexes (Figure 1B, 2 and S2). Cluster stability was estimated as Jaccard means, which were $>0 \cdot 8$ for all clusters regardless of sex.

Cluster 1, including $6.4 \%$ of the clustered patients (referred to as SAID, Severe Autoimmune Diabetes) was characterized by early onset, relatively low BMI, poor metabolic control, insulin deficiency, and presence of GADA (Table S2). Cluster 2 (SIDD, Severe Insulin Deficient Diabetes) encompassing $17 \cdot 5 \%$ of patients was GADA negative but otherwise similar to SAID: low age at onset, relatively low BMI, low insulin secretion (low HOMA2-B) and poor metabolic 
control. Cluster 3 (SIRD, Severe Insulin Resistant Diabetes; 15·3\%) was characterized by insulin resistance (high HOMA2-IR) and high BMI. Cluster 4 was also characterized by obesity but not by insulin resistance (MOD, Mild Obese Diabetes; 21.6\%). Patients in cluster 5 were older (MARD, Mild Age-Related Diabetes; 39·1\%) but showed, as cluster 4, only modest metabolic derangements.

We used three independent cohorts to replicate the clustering: the Scania Diabetes Registry (SDR, N=1,466), ANDIU (All New Diabetics in Uppsala, N=844) and DIREVA (Diabetes Registry Vaasa, $\mathrm{N}=3,485)$. In SDR, the optimal number of clusters was also estimated to be 5 and k-means $(k=4)$ and TwoStep clustering yielded very similar results (92.4\% clustered identically). Patient distributions and cluster characteristics were similar to ANDIS (Figure 1C, S3A and B). Jaccard bootstrap means were $>0.8$ for all clusters. K-means clustering in ANDIU also replicated the results from ANDIS (Figure 1D, S3D). In the DIREVA cohort we tested whether clustering would give similar results in patients with longer diabetes duration as newly-diagnosed diabetes. Encouragingly, the results were comparable in recently diagnosed patients (diabetes duration $<2$ years, $\mathrm{N}=878$ ) and patients with longer duration (mean 10·15 $\pm 10 \cdot 34 ; \mathrm{N}=2607$; Figure 1E and $\mathrm{F}$, S4 A and B).

To be clinically useful patients would need to be assigned to clusters without de novo clustering of a full cohort. Therefore, we assigned patients in replication cohorts to clusters based on which cluster they were most similar to, calculated as their Euclidian distance from the nearest cluster center derived from ANDIS coordinates and found similar distributions (Figure S3 C and E, Figure S4 B and D).

To evaluate the clinical utility of the clustering we compared disease progression, treatment and development of diabetic complications between clusters in ANDIS. SAID and SIDD had markedly higher $\mathrm{HbA1c}$ at diagnosis compared to other clusters, a difference persisting 
throughout the follow-up period (Figure 3A). Ketoacidosis at diagnosis was most frequent in SAID $(30 \cdot 5 \%)$ and SIDD $(25 \cdot 1 \%)$, compared to others $(<5 \%$, Figure S5). HbA1c was the strongest predictor of ketoacidosis at diagnosis (OR $2 \cdot 73[2 \cdot 46-3 \cdot 03], \mathrm{p}=2 \cdot 0 \times 10^{-82}$, per $1 \mathrm{SD}$ change, Table S4). SIRD had the highest prevalence of non-alcoholic fatty liver disease (NAFLD, Figure S6). Zinc transporter $8 \mathrm{~A}$ antibodies were primarily seen in SAID (27.3\% positive compared to $<1.5 \%$ in other clusters; Figure S7).

At registration, insulin had been prescribed to $41 \cdot 9 \%$ of patients in SAID and to $29 \cdot 1 \%$ in SIDD but to $<4 \%$ of patients in clusters 3-5 (Table S2, Figure S8). Time to insulin was shortest in SAID (HR 17·05[14·34-20·28] compared to MARD, Figure 4A, Table S5), followed by SIDD

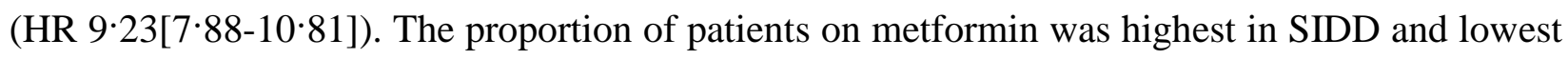
in SAID (Figure S8, 4B), but also surprisingly low in SIRD which should benefit most from metformin, demonstrating that traditional classification is unable to tailor treatment to the underlying pathogenic defects. Metformin is contra-indicated in patients with impaired kidney function and sometimes discontinued because of adverse gastrointestinal reactions. However, these factors had obviously not much influence on the use of metformin at this early stage of the disease, as the same distributions of patients were observed for initial treatment, and exclusion of patients with reduced kidney function (eGFR $<60 \mathrm{ml} / \mathrm{min}$ ) at their first check-up, had no major effect on the proportions of patients on metformin (Figure S9). Time to a second oral diabetes treatment was also shortest in SIDD (Figure 4C, Table S5). Time to reaching the treatment goal (HbA1c <52 mmol/mol) was longest for SIDD (Figure 4D).

In ANDIS, SIRD had the highest risk of developing chronic kidney disease (CKD) during followup of $3 \cdot 9 \pm 2 \cdot 3$ years (Table S6). For CKD stage $3 \mathrm{~A}(\mathrm{eGFR}<60 \mathrm{ml} / \mathrm{min}$ ) the age and sex adjusted risk was more than 2-fold higher $\left(\mathrm{HR} 2 \cdot 41[2 \cdot 08-2 \cdot 79], \mathrm{p}=1 \cdot 4 \times 10^{-31}\right.$, Figure $\left.\mathrm{S} 10 \mathrm{~A}\right)$ and for stage 3B (eGFR<45 ml/min) >3-fold higher compared with the reference cluster MARD (HR 
$3 \cdot 34[2 \cdot 59-4 \cdot 30], p=8 \cdot 3 \times 10^{-21}$, Figure 3B). SIRD also showed higher risk of diabetic kidney

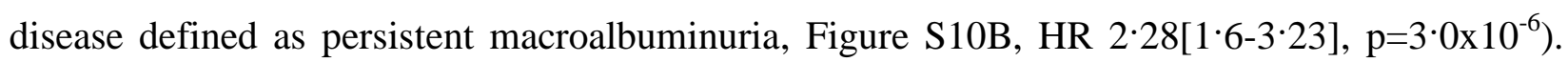
Also in the SDR cohort (follow-up $11 \cdot 0 \pm 4 \cdot 4$ years), SIRD had the highest risk of CKD (Table S8), and macroalbuminuria ( $\mathrm{HR} 2 \cdot 36[1 \cdot 54-3 \cdot 61], \mathrm{p}=7 \cdot 7 \times 10^{-5}$, Figure 3D). Strikingly, SIRD patients had five times higher risk of ESRD than MARD (HR 5.04[2.76-9.23], $\mathrm{p}=1 \cdot 5 \times 10^{-7}$, Figure 3E). The increased prevalence of kidney disease in SIRD was also confirmed in the DIREVA cohort (Figure S13).

Early signs of diabetic retinopathy (mean duration 135 days) were more common in SIDD than in other clusters (OR $1 \cdot 6[1 \cdot 3-1 \cdot 9], \mathrm{p}=9 \cdot 7 \times 10^{-7}$ compared to MARD; Figure S11A). The higher prevalence of retinopathy in SIDD was replicated in the ANDIU (Figure S11B) and SDR cohorts (HR 1·49[1·17-1·89], $\mathrm{p}=0 \cdot 001$; Figure 3F, Table S9).

Although risk of coronary events and stroke was lowest in the SAID, SIDD and MOD clusters (Figure 3C, Table S7) the differences became nominal after adjusting for age. No significant differences in age-adjusted risk of coronary events or stroke were seen between clusters in SDR (Figure S10, Table S10).

Finally, we analyzed genetic loci previously shown to be associated with T2D and related traits ${ }^{17}$ to see if we could obtain genetic support for the observed differences between the clusters (Table 1). Each cluster was compared to a non-diabetic cohort (MDC-CVA) from the same geographical region. ${ }^{9}$ Notably, no genetic variant was associated $(\mathrm{p}<0 \cdot 01)$ with all clusters (Table S11). Strikingly, the strongest T2D-associated variant in the TCF7L2 (rs7903146) gene ${ }^{18}$ was associated with SIDD, MOD and MARD, but not with SIRD (Table 1). The difference between cluster odds ratios was significant even after Bonferroni correction for the 77 tests performed. A variant in the IGF2BP2 (rs4402960) gene was associated with SIDD and MARD but not with SIRD or MOD. The variant rs10401969 in the TM6SF2 gene previously associated with 
NAFLD $^{19}$ was most strongly associated with SIRD but not with MOD suggesting that SIRD is characterized by unhealthy (metabolic syndrome) and MOD by more healthy obesity.

\section{Discussion}

Taken together, this study demonstrates that this new clustering is superior in terms of prediction of disease progression, particularly development of diabetic complications compared to the classical diabetes classification. Importantly, this prediction can be made already at diagnosis. In contrast to previous attempts to dissect the heterogeneity of diabetes ${ }^{20}$ we have used variables reflecting key aspects of the diabetic disease that are monitored in patients. Thus, this clustering can easily be applied to both existing diabetes cohorts (e.g. from drug trials) and patients in the diabetes clinic. A web-tool to assign patients to specific clusters, provided above variables have been measured, is under development.

While SAID overlapped with T1D and LADA, SIDD and SIRD represent two novel severe forms of diabetes previously masked within T2D. It would be reasonable to target intensified treatment resources to these clusters to prevent diabetic complications. SIRD had a markedly increased risk of kidney complications, reinforcing the association between insulin resistance and kidney disease. $^{21}$ Insulin resistance has been associated with higher salt sensitivity, glomerular hypertension, hyperfiltration, and declining renal function, all hallmarks of diabetic kidney disease (DKD). ${ }^{22}$ The increased incidence of DKD in this study was seen in spite of relatively low HbA1c, suggesting that glucose-lowering therapy is not the ultimate way of preventing DKD. In support of this, mice with podocyte-specific knockout of the insulin receptor, mimicking the reduced insulin signaling seen in insulin resistant individuals, developed DKD even during normoglycemic conditions. ${ }^{23}$ Although differences were not as pronounced as seen 
for DKD, insulin deficiency and/or hyperglycemia seem to be important triggers of retinopathy with the highest prevalence observed in SIDD.

We cannot at this stage claim that the new clusters represent different etiologies of diabetes, nor that this represents the optimal classification of diabetes subtypes. The fact that clustering gave similar results in newly diagnosed patients and patients with longer diabetes duration, and that the key variable C-peptide remained relatively stable over time (Figure S13), suggests that the clusters are stable and at least partially mechanistically distinct rather than representing different stages of the same disease. The differences in genetic associations also support this view. Notably, hepatic insulin resistance seems to be a feature of NAFLD, as the NAFLD-associated SNP in the TM6SF2 gene was associated with SIRD but not with MOD. However, it still needs to be shown in prospective studies whether patients (especially from the periphery of clusters) can move between clusters and the exact overlap of weaker association signals will need to be investigated in larger cohorts. It might also be possible to refine the stratification further by including additional cluster variables e.g. biomarkers, genotypes or genetic risk scores.

Taken together, the current data demonstrate that the combined information from a few variables central to the development of diabetes is superior to the measurement of only one metabolite, glucose. By combining this information from diagnosis with information in the health care system this study provides a first step towards a more precise, clinically useful, stratification, representing an important step towards precision medicine in diabetes. This clustering also opens up for randomized trials targeting insulin secretion in SIDD and insulin resistance in SIRD.

\section{Acknowledgements}

We thank all the patients and the health care providers across Scania and Ostrobothnia for their support and their willingness to participate. We would also like to thank Johan Hultman, Jasmina 
Kravic, Maria Fälemark, Christina Rosborn, Gabriella Gremsperger, Maria Sterner, Malin Neptin, Lisa Sundman, Paula Kokko, Carin Gustavsson and Ulrika Blom-Nilsson for excellent technical and administrative support. Finally we would like to thank Rita Jedlert and Region Skåne (Scania County) as well as the ANDIS steering committee for their support.

\section{Financial Support}

Supported by grants from the Swedish Research Council (including project grants Dnr.521-20103490 and infrastructure grants Dnr. 2010-5983 and Dnr 2012-5538 to LG), Linnéus grant 3492006-237, a strategic research grant (Exodiab Dnr 2009-1039), an ERC Advanced Research grant (GA 269045) and Academy of Finland (grants no. 263401 and 267882) to LG, Novo Nordisk Foundation and ALF. DIREVA was supported by the Vasa Hospital district. LG has received grants from Pfizer, Lilly and Novartis.

\section{Declaration of interest}

The authors have no conflicts of interest.

\section{Author contributons}

EA, PS, PV, TT, AHR and LG contributed with the conception of the work. EA, PS, AK, MM, MD, AC, PV, YW, NS, PS, HM, EL, OM, OH, UM, ÅL, KL, TF, TT, AHR and LG contributed to the data collection. EA, PS, MM, RP, DMA and PA contributed to the data analysis. EA, PS and LG drafted the article. All authors contributed in the interpretation of data and critical revision of the article. All authors gave final approval of the version to be published. 


\section{References}

1. Collaboration NCDRF. Worldwide trends in diabetes since 1980: a pooled analysis of 751 population-based studies with 4.4 million participants. Lancet 2016; 387(10027): 1513-30.

2. Tuomi T, Groop LC, Zimmet PZ, Rowley MJ, Knowles W, Mackay IR. Antibodies to Glutamic Acid Decarboxylase Reveal Latent Autoimmune Diabetes Mellitus in Adults With a Non-Insulin-Dependent Onset of Disease. Diabetes 1993; 42(2): 359-62.

3. Froguel P, Zouali H, Vionnet N, et al. Familial hyperglycemia due to mutations in glucokinase. Definition of a subtype of diabetes mellitus. N Engl J Med 1993; 328(10): 697-702.

4. Yamagata K, Oda N, Kaisaki PJ, et al. Mutations in the hepatocyte nuclear factor-1alpha gene in maturity-onset diabetes of the young (MODY3). Nature 1996; 384(6608): 455-8.

5. Reddy MA, Zhang E, Natarajan R. Epigenetic mechanisms in diabetic complications and metabolic memory. Diabetologia 2015; 58(3): 443-55.

6. Brownlee M. The pathobiology of diabetic complications: a unifying mechanism. Diabetes 2005; 54(6): 1615-25.

7. Pearson ER, Flechtner I, Njolstad PR, et al. Switching from insulin to oral sulfonylureas in patients with diabetes due to Kir6.2 mutations. N Engl J Med 2006; 355(5): 467-77.

8. Lindholm E, Agardh E, Tuomi T, Groop L, Agardh CD. Classifying diabetes according to the new WHO clinical stages. Eur J Epidemiol 2001; 17(11): 983-9.

9. Manjer J, Carlsson S, Elmstahl S, et al. The Malmo Diet and Cancer Study: representativity, cancer incidence and mortality in participants and non-participants. Eur $J$ Cancer Prev 2001; 10(6): 489-99. 
10. Rahmati K, Lernmark A, Becker C, et al. A comparison of serum and EDTA plasma in the measurement of glutamic acid decarboxylase autoantibodies (GADA) and autoantibodies to islet antigen-2 (IA-2A) using the RSR radioimmunoassay (RIA) and enzyme linked immunosorbent assay (ELISA) kits. Clin Lab 2008; 54(7-8): 227-35.

11. Tuomi T, Carlsson A, Li H, et al. Clinical and genetic characteristics of type 2 diabetes with and without GAD antibodies. Diabetes 1999; 48(1): 150-7.

12. Vaziri-Sani F, Delli AJ, Elding-Larsson H, et al. A novel triple mix radiobinding assay for the three ZnT8 (ZnT8-RWQ) autoantibody variants in children with newly diagnosed diabetes. Journal of immunological methods 2011; 371(1-2): 25-37.

13. Levy JC, Matthews DR, Hermans MP. Correct homeostasis model assessment (HOMA) evaluation uses the computer program. Diabetes Care 1998; 21(12): 2191-2.

14. Levey AS, Stevens LA, Schmid $\mathrm{CH}$, et al. A new equation to estimate glomerular filtration rate. Ann Intern Med 2009; 150(9): 604-12.

15. Martinell M, Dorkhan M, Stalhammar J, Storm P, Groop L, Gustavsson C. Prevalence and risk factors for diabetic retinopathy at diagnosis (DRAD) in patients recently diagnosed with type 2 diabetes (T2D) or latent autoimmune diabetes in the adult (LADA). J Diabetes Complications 2016; 30(8): 1456-61.

16. Hennig C. Cluster-wise assessment of cluster stability. Comput Stat Data An 2007; 52(1): 258-71.

17. Prasad RB, Groop L. Genetics of type 2 diabetes-pitfalls and possibilities. Genes (Basel) 2015; 6(1): 87-123. 
18. Lyssenko V, Lupi R, Marchetti P, et al. Mechanisms by which common variants in the TCF7L2 gene increase risk of type 2 diabetes. J Clin Invest 2007; 117(8): 2155-63.

19. Liu YL, Reeves HL, Burt AD, et al. TM6SF2 rs58542926 influences hepatic fibrosis progression in patients with non-alcoholic fatty liver disease. Nature communications 2014; 5: 4309.

20. Li L, Cheng WY, Glicksberg BS, et al. Identification of type 2 diabetes subgroups through topological analysis of patient similarity. Science translational medicine 2015; 7(311): 311 ra174.

21. Groop L, Ekstrand A, Forsblom C, et al. Insulin resistance, hypertension and microalbuminuria in patients with type 2 (non-insulin-dependent) diabetes mellitus. Diabetologia 1993; 36(7): 642-7.

22. Gnudi L, Coward RJ, Long DA. Diabetic Nephropathy: Perspective on Novel Molecular Mechanisms. Trends Endocrinol Metab 2016; 27(11): 820-30.

23. Welsh GI, Hale LJ, Eremina V, et al. Insulin signaling to the glomerular podocyte is critical for normal kidney function. Cell metabolism 2010; 12(4): 329-40. 

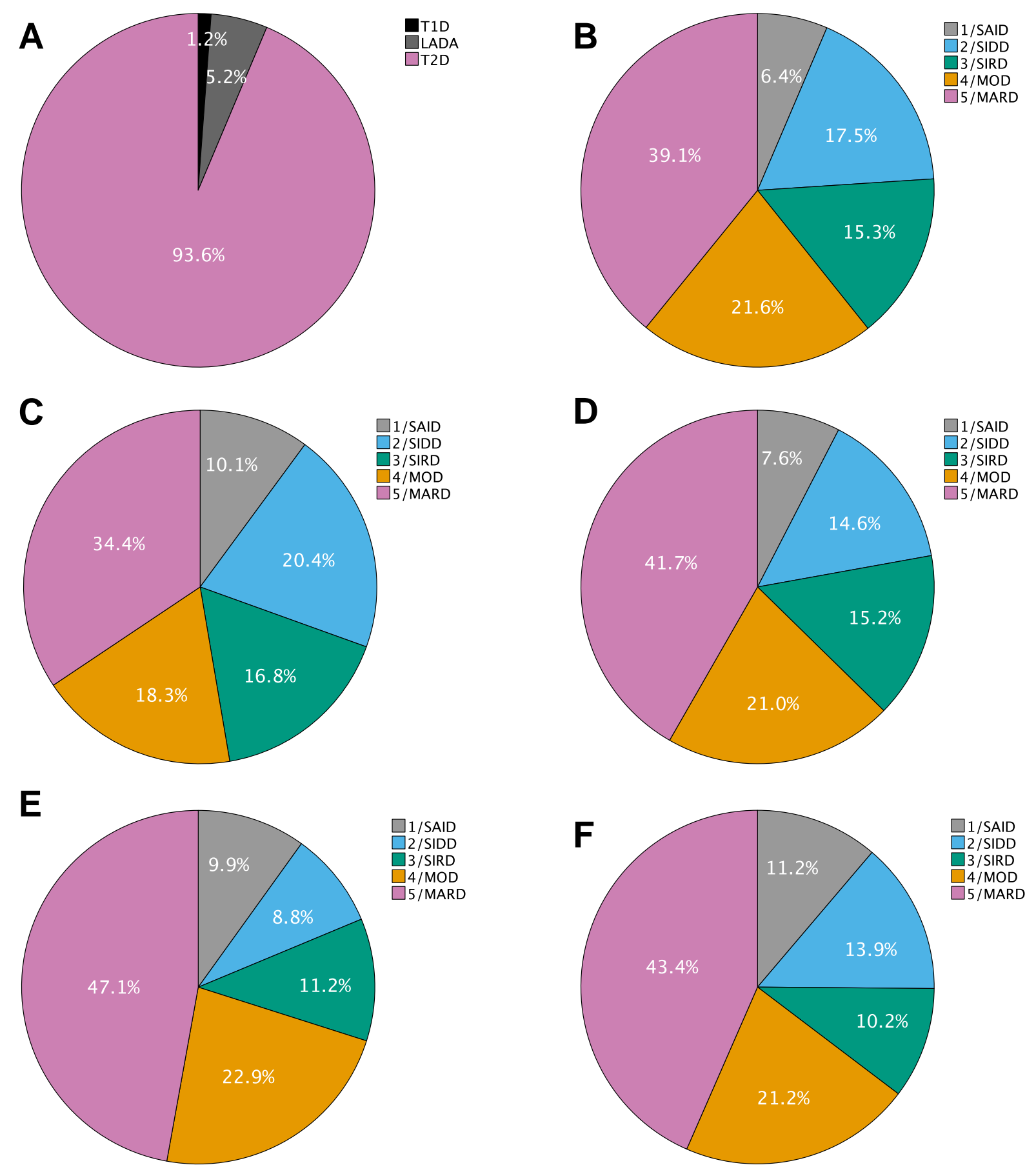

Figure 1. Patient distribution using different methods for classification.

Distribution of ANDIS patients included in the clustering using (A) traditional classification and

(B) k-means clustering. Distribution of patients using k-means clustering in SDR (C), ANDIU

(D) and in DIREVA stratified for newly diagnosed (E) and long duration (F). 

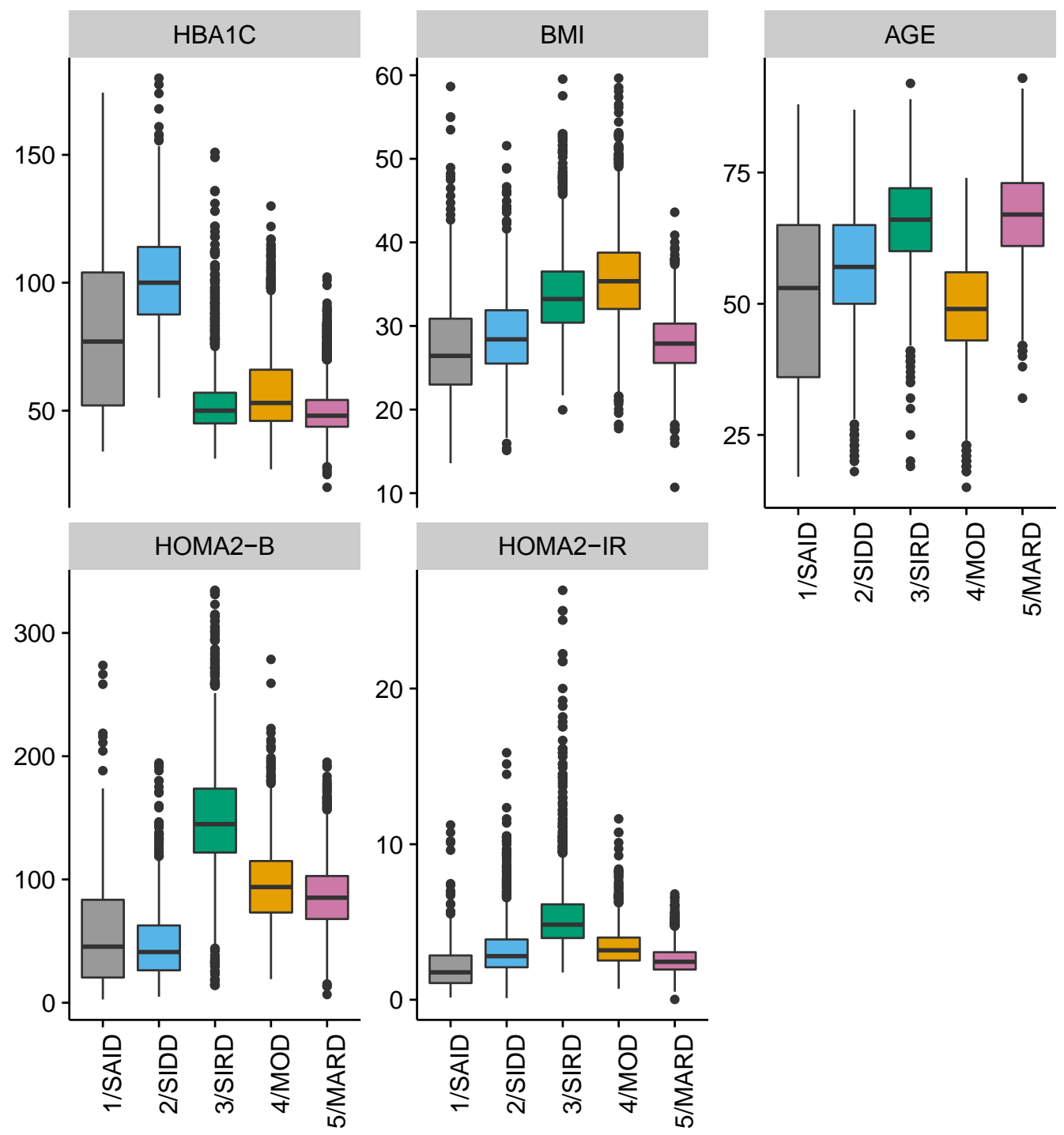

\section{Figure 2. Cluster characteristics in ANDIS.}

Distributions of HbA1c (mmol/mol) at diagnosis, and BMI (kg/m2), age (years), HOMA2-B (\%) and HOMA2-IR at registration in ANDIS for each cluster. K-means clustering was performed separately for men and women, pooled data are shown here (cluster 2-5). 

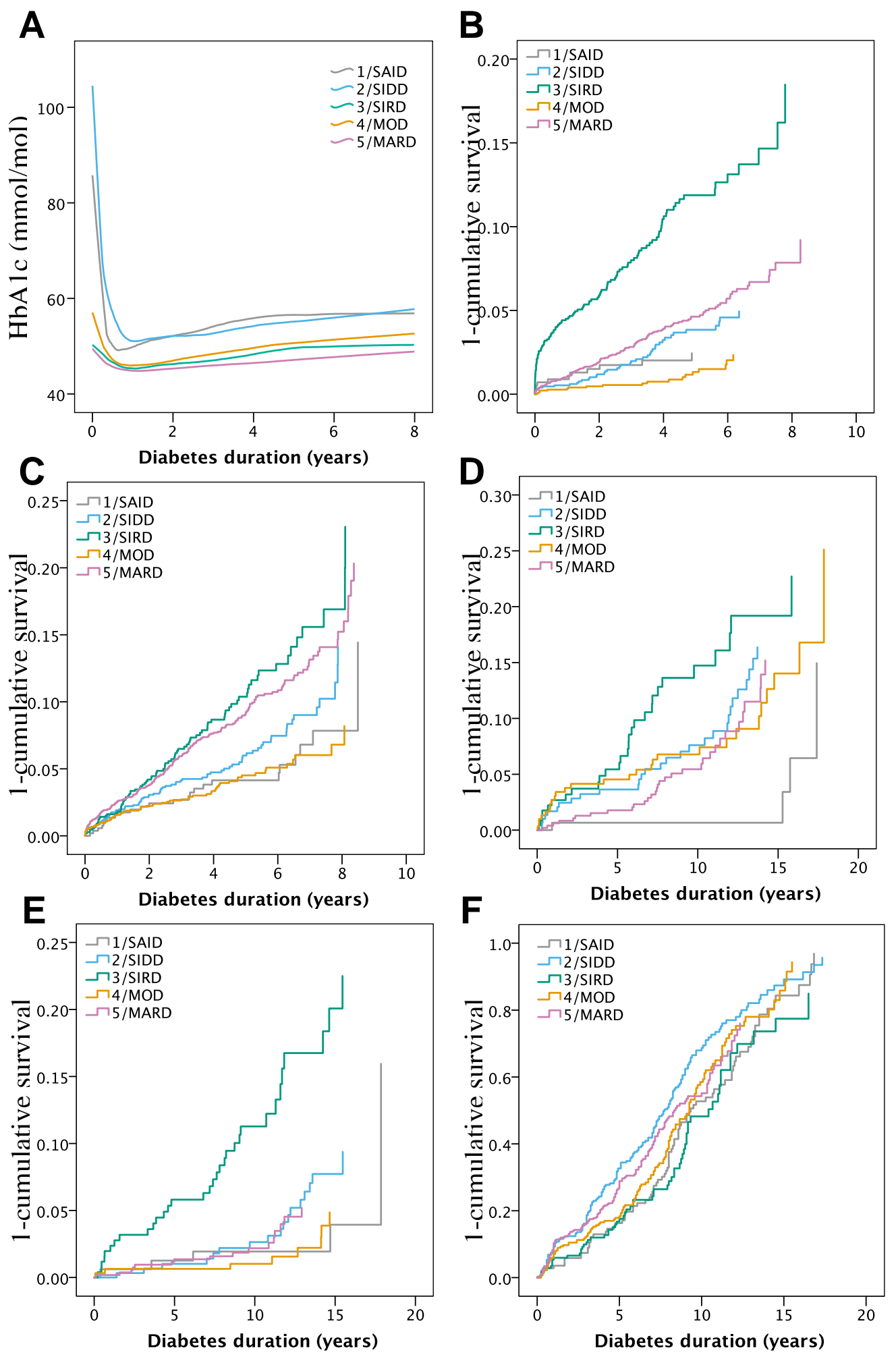


\section{Figure 3. Progression of disease over time by cluster}

Figure 3 shows mean HbA1c over time by loess regression (A), time to CKD at least stage 3B (B) and coronary events (C) in ANDIS; Macroalbuminuria (D), ESRD (E) and mild nonproliferative to proliferative diabetic retinopathy $(\mathrm{F})$, in the SDR cohort. Kidney function was not tested at diagnosis and therefore set to the first screening date. Thus it is not known how many were already affected at diagnosis. 
A
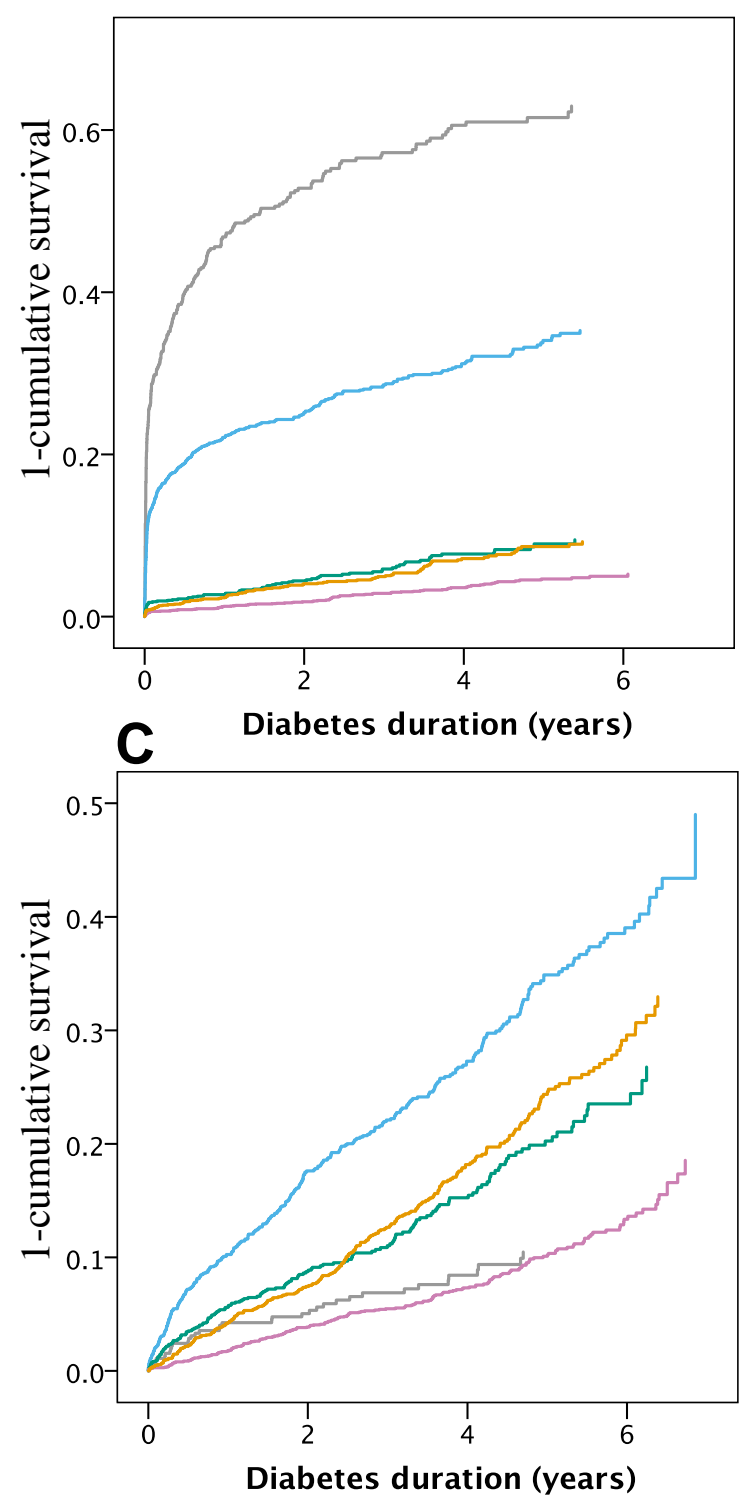

B
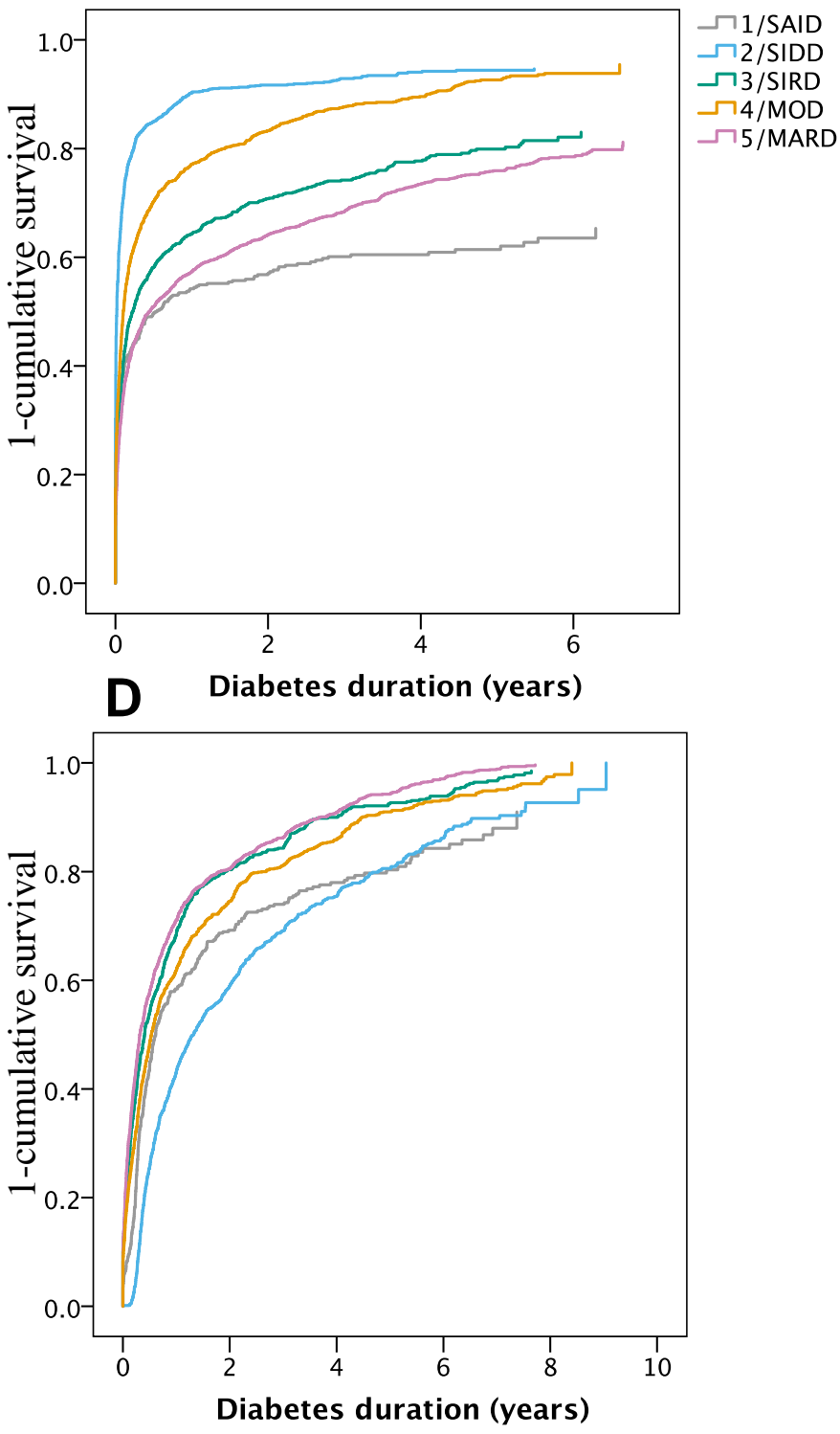

Figure 4. Antidiabetic therapy in ANDIS during follow-up.

Cox regressions of time to treatment with insulin (A), metformin (B), oral medication other than metformin (C) or (D) reaching treatment goal (HbA1c $<52 \mathrm{mmol} / \mathrm{mol})$. Cluster $1 / \mathrm{SAID}$ had the shortest time to insulin. Cluster 2/SIDD had a shorter time to insulin, metformin and any other oral medication than clusters 3 to 5 . Despite this, cluster 2/SIDD reached the treatment goal significantly later than other clusters. For statistics see table S5. 
Table 1. Genetic associations with specific ANDIS clusters reaching at least nominal significance for difference between clusters 2 to 5.

\begin{tabular}{|c|c|c|c|c|c|c|c|c|c|c|c|c|c|}
\hline & & & & \multicolumn{2}{|l|}{ 1/SAID } & \multicolumn{2}{|l|}{ 2/SIDD } & \multicolumn{2}{|l|}{ 3/SIRD } & \multicolumn{2}{|l|}{ 4/MOD } & \multicolumn{2}{|l|}{ 5/MARD } \\
\hline & & & & $\mathrm{N}=313$ & & $\mathrm{~N}=676$ & & $\mathrm{~N}=603$ & & $\mathrm{~N}=727$ & & $\mathrm{~N}=1341$ & \\
\hline SNP & Gene & EA/ NEA & MAF & OR & $\mathrm{P}$ & OR & $\mathrm{P}$ & OR & $\mathrm{P}$ & OR & $\mathrm{P}$ & OR & $\mathrm{P}$ \\
\hline rs7903146 & TCF7L2 & $\mathrm{T} / \mathrm{C}$ & $0 \cdot 26$ & $1 \cdot 17(0 \cdot 97-1 \cdot 40)$ & 0.077 & $1 \cdot 51(1 \cdot 33-1 \cdot 71)$ & $2 \cdot 8 \times 10^{-10}$ & $1 \cdot 00(0 \cdot 87-1 \cdot 15)$ & $0 \cdot 86$ & $1 \cdot 38(1 \cdot 21-1 \cdot 56)$ & $5 \cdot 7 \times 10^{-7}$ & $1 \cdot 41(1 \cdot 28-1 \cdot 55)$ & $1 \cdot 1 \times 10^{-12}$ \\
\hline rs1111875 & HHEX/IDE & $\mathrm{G} / \mathrm{A}$ & $0 \cdot 41$ & $1 \cdot 16(0 \cdot 98-1 \cdot 38)$ & $0 \cdot 104$ & $1 \cdot 21(1 \cdot 07-1 \cdot 37)$ & $0 \cdot 0045$ & $1 \cdot 05(0 \cdot 92-1 \cdot 19)$ & $0 \cdot 51$ & $0 \cdot 94(0 \cdot 84-1 \cdot 06)$ & $0 \cdot 31$ & $1 \cdot 11(1 \cdot 02-1 \cdot 22)$ & $0 \cdot 023$ \\
\hline rs10811661 & CDKN2B & $\mathrm{T} / \mathrm{C}$ & $0 \cdot 16$ & $0 \cdot 87(0 \cdot 70-1 \cdot 08)$ & $0 \cdot 242$ & $1 \cdot 33(1 \cdot 11-1 \cdot 59)$ & $0 \cdot 0014$ & $0 \cdot 98(0 \cdot 83-1 \cdot 17)$ & $0 \cdot 85$ & $0 \cdot 99(0 \cdot 84-1 \cdot 16)$ & $0 \cdot 92$ & $1 \cdot 18(1 \cdot 04-1 \cdot 33)$ & $0 \cdot 0054$ \\
\hline rs10830963 & MTNR1B & $\mathrm{G} / \mathrm{C}$ & $0 \cdot 29$ & $0 \cdot 84(0 \cdot 70-1 \cdot 01)$ & $0 \cdot 054$ & $0 \cdot 93(0 \cdot 82-1 \cdot 07)$ & $0 \cdot 26$ & $0 \cdot 89(0 \cdot 77-1 \cdot 02)$ & $0 \cdot 055$ & $1 \cdot 13(1 \cdot 00-1 \cdot 28)$ & $0 \cdot 067$ & $1 \cdot 05(0 \cdot 96-1 \cdot 15)$ & $0 \cdot 29$ \\
\hline rs13266634 & SLC30A8 & $\mathrm{T} / \mathrm{C}$ & $0 \cdot 31$ & $0 \cdot 98(0 \cdot 82-1 \cdot 17)$ & $0 \cdot 78$ & $0 \cdot 93(0 \cdot 82-1 \cdot 06)$ & $0 \cdot 23$ & $1 \cdot 11(0 \cdot 97-1 \cdot 27)$ & $0 \cdot 11$ & $1 \cdot 07(0 \cdot 94-1 \cdot 21)$ & $0 \cdot 30$ & $0 \cdot 92(0 \cdot 83-1 \cdot 01)$ & $0 \cdot 046$ \\
\hline rs12970134 & MC4R & $\mathrm{G} / \mathrm{A}$ & $0 \cdot 27$ & $0 \cdot 95(0 \cdot 79-1 \cdot 14)$ & 0.52 & $0 \cdot 97(0 \cdot 85-1 \cdot 11)$ & $0 \cdot 54$ & $0 \cdot 99(0 \cdot 86-1 \cdot 13)$ & 0.59 & $0 \cdot 87(0 \cdot 77-0 \cdot 99)$ & $0 \cdot 023$ & $1 \cdot 07(0 \cdot 97-1 \cdot 18)$ & $0 \cdot 18$ \\
\hline rs10401969 & TM6SF2 & $\mathrm{T} / \mathrm{C}$ & $0 \cdot 10$ & $0 \cdot 75(0 \cdot 58-0 \cdot 97)$ & $0 \cdot 038$ & $0.69(0 \cdot 58-0 \cdot 83)$ & $0 \cdot 00021$ & $0 \cdot 62(0 \cdot 52-0 \cdot 75)$ & $3 \cdot 1 \times 10^{-6}$ & $0 \cdot 89(0 \cdot 73-1 \cdot 07)$ & $0 \cdot 26$ & $0 \cdot 77(0 \cdot 67-0 \cdot 89)$ & $0 \cdot 00046$ \\
\hline rs17271305 & VPS13C & $\mathrm{G} / \mathrm{A}$ & $0 \cdot 40$ & $1 \cdot 00(0 \cdot 84-1 \cdot 19)$ & 0.93 & $0 \cdot 97(0 \cdot 86-1 \cdot 10)$ & $0 \cdot 84$ & $1 \cdot 11(0 \cdot 98-1 \cdot 26)$ & $0 \cdot 09$ & $0 \cdot 88(0 \cdot 78-0 \cdot 99)$ & $0 \cdot 049$ & $0 \cdot 93(0 \cdot 85-1 \cdot 02)$ & $0 \cdot 17$ \\
\hline rs11920090 & SLC2A2 & $\mathrm{T} / \mathrm{A}$ & $0 \cdot 13$ & $0 \cdot 94(0 \cdot 74-1 \cdot 20)$ & $0 \cdot 54$ & $0 \cdot 83(0 \cdot 70-0 \cdot 99)$ & $0 \cdot 016$ & $0 \cdot 91(0 \cdot 76-1 \cdot 09)$ & $0 \cdot 23$ & $0 \cdot 97(0 \cdot 82-1 \cdot 16)$ & $0 \cdot 63$ & $1 \cdot 08(0 \cdot 95-1 \cdot 24)$ & $0 \cdot 44$ \\
\hline rs5219 & KCNJ11 & $\mathrm{T} / \mathrm{C}$ & $0 \cdot 38$ & $1 \cdot 05(0 \cdot 88-1 \cdot 25)$ & $0 \cdot 61$ & $1 \cdot 18(1 \cdot 04-1 \cdot 34)$ & $0 \cdot 012$ & $1 \cdot 03(0 \cdot 90-1 \cdot 18)$ & $0 \cdot 67$ & $1 \cdot 28(1 \cdot 13-1 \cdot 44)$ & $0 \cdot 00012$ & $1 \cdot 10(1 \cdot 01-1 \cdot 21)$ & $0 \cdot 032$ \\
\hline rs7961581 & TSPAN8 & $\mathrm{T} / \mathrm{C}$ & $0 \cdot 26$ & $0 \cdot 97(0 \cdot 80-1 \cdot 17)$ & 0.69 & $1 \cdot 05(0 \cdot 92-1 \cdot 21)$ & 0.55 & $1 \cdot 13(0 \cdot 98-1 \cdot 31)$ & $0 \cdot 11$ & $0 \cdot 99(0 \cdot 87-1 \cdot 13)$ & $0 \cdot 80$ & $0 \cdot 92(0 \cdot 84-1 \cdot 02)$ & $0 \cdot 11$ \\
\hline
\end{tabular}

Maximum likelihood estimation using geographically matched non-diabetic individuals as controls (N=2754) EA=Effect allele; NEA=Non effect allele 


\section{Supplementary Materials}

\section{Supplementary figures}

A

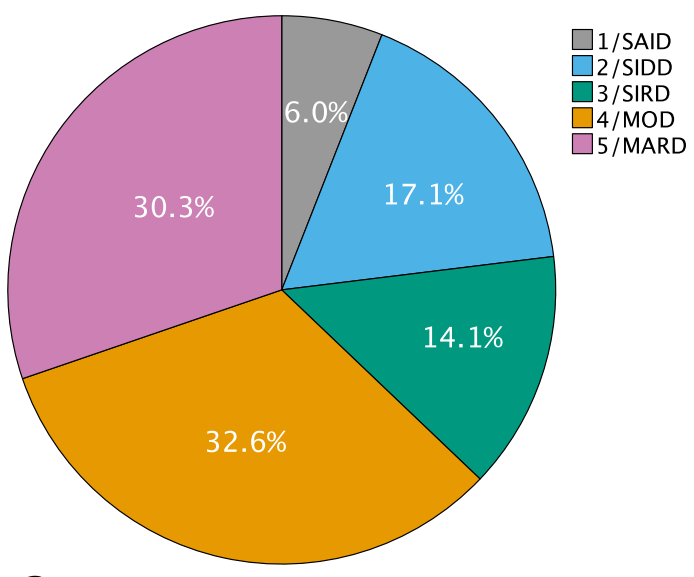

C

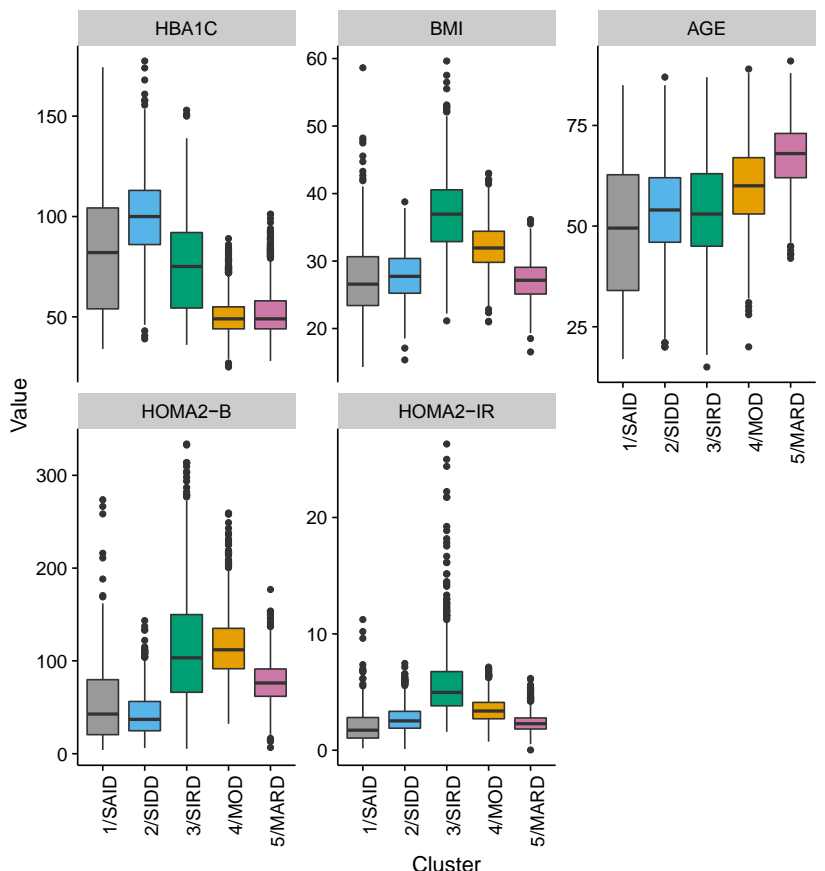

B

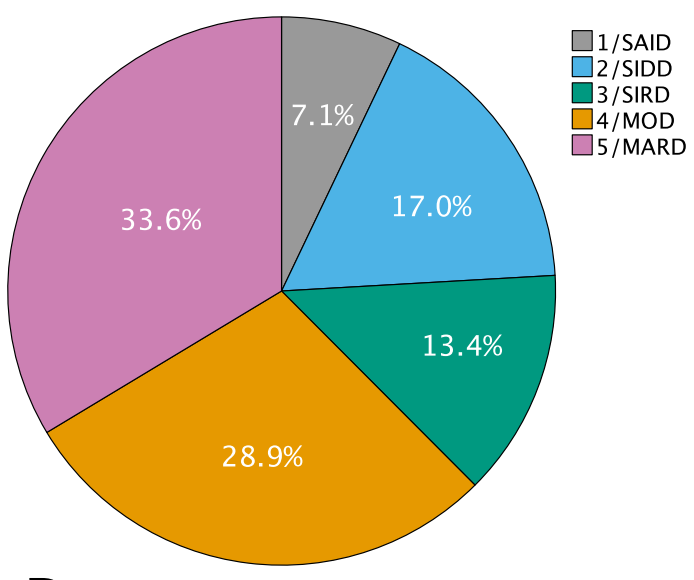

D

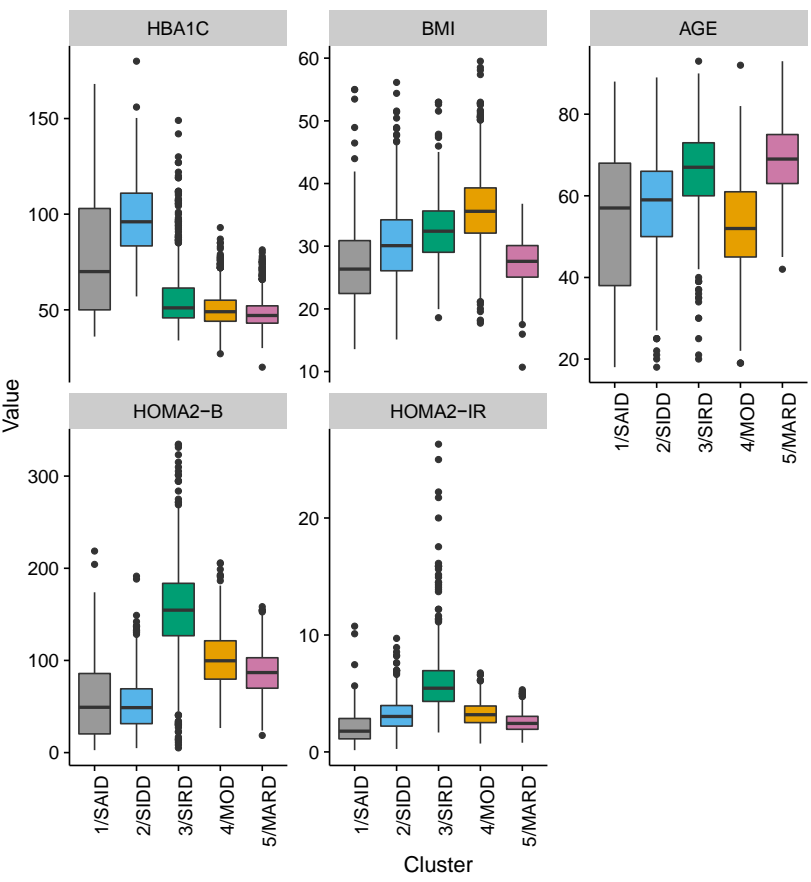

Figure S1. Results of sex-specific TwoStep clustering in ANDIS.

The distribution of patients based on TwoStep cluster analysis in the ANDIS (All New Diabetes in Scania) cohort was similar in (A) men and (B) women. The different clusters in men (C) and women (D) had similar distribution of the variables used for clustering, i.e. of HAalc (mmol/mol) at diagnosis; BMI $(\mathrm{kg} / \mathrm{m} 2)$, age (years), HOMA2-B (\%) and HOMA2-IR at registration, except for some differences in clusters 3 and 4 (women in cluster 4 were older and less obese compared to men in cluster 3 ). 


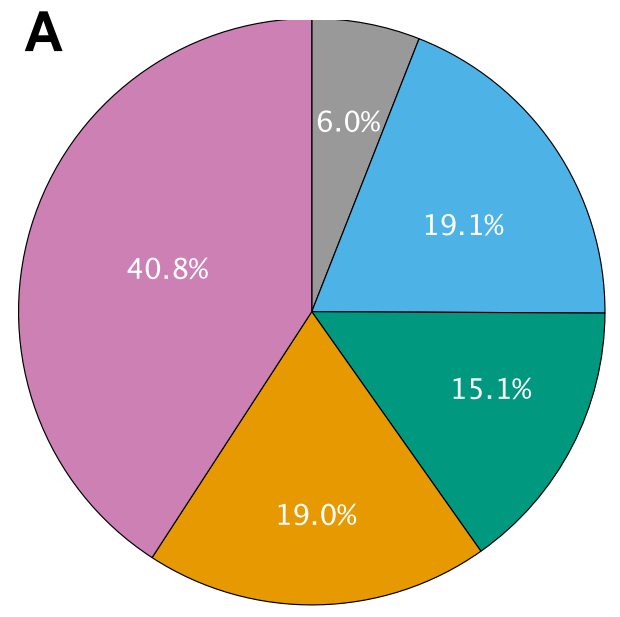

C

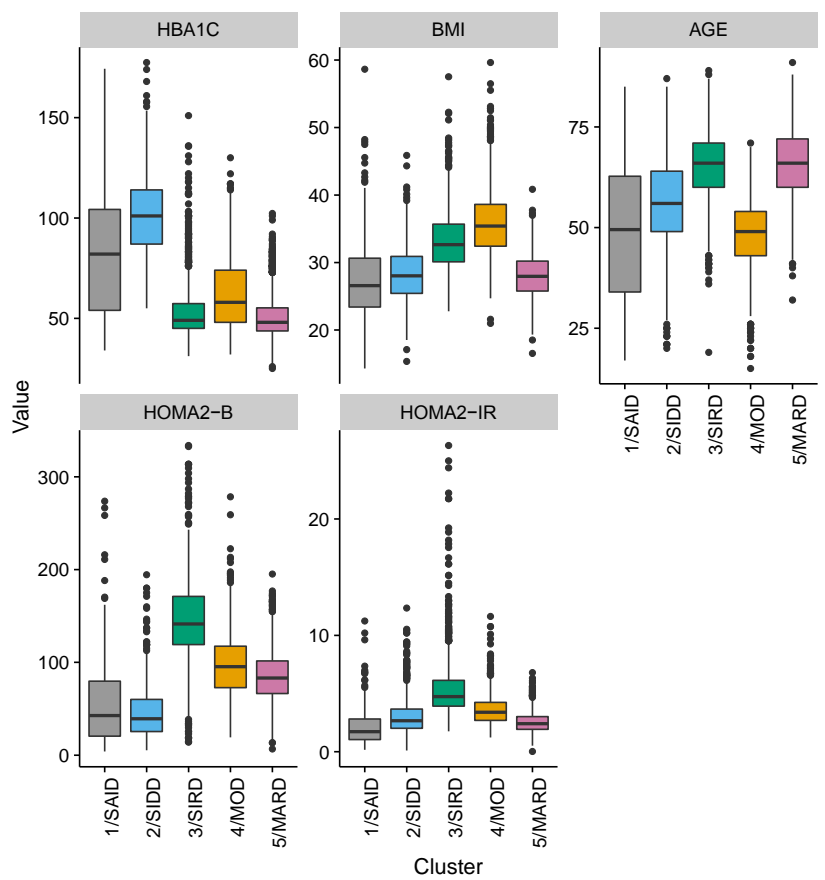

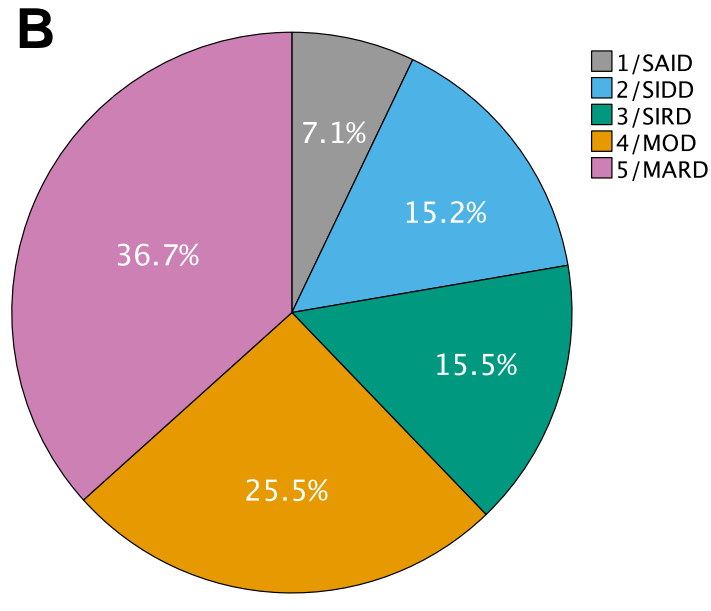

D

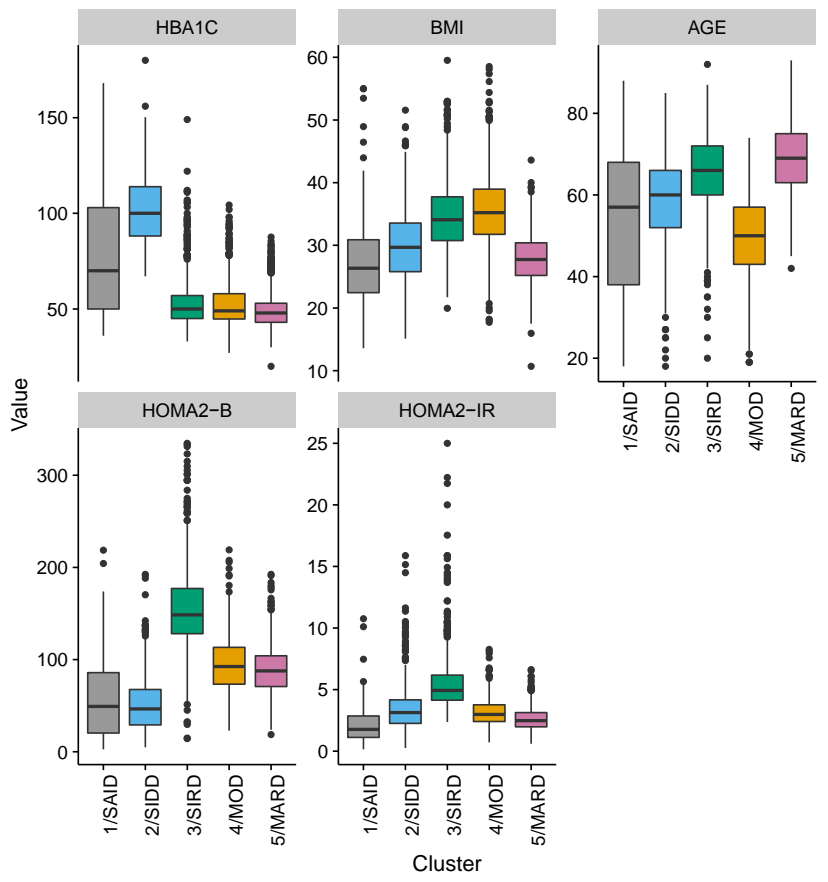

Figure S2. Results of sex-specific k-means clustering in ANDIS.

The distribution of patients based on k-means cluster analysis in ANDIS was similar in men (A) and women (B). The different clusters in men (C) and women (D) had similar distribution of the variables used for clustering, i.e. of HAa1c $(\mathrm{mmol} / \mathrm{mol})$ at diagnosis; BMI ( $\mathrm{kg} / \mathrm{m} 2)$, age (years), HOMA2-B (\%) and HOMA2-IR at registration. 
bioRxiv preprint doi: https://doi.org/10.1101/186387; this version posted September 8, 2017. The copyright holder for this preprint (which was

A
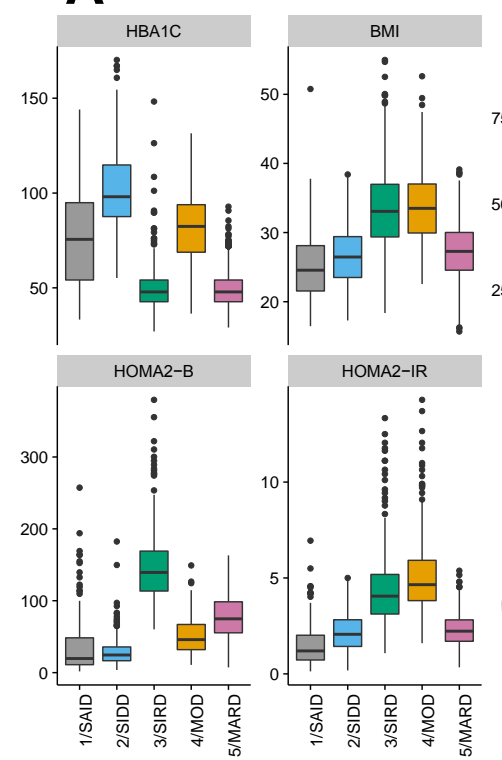

\section{C}
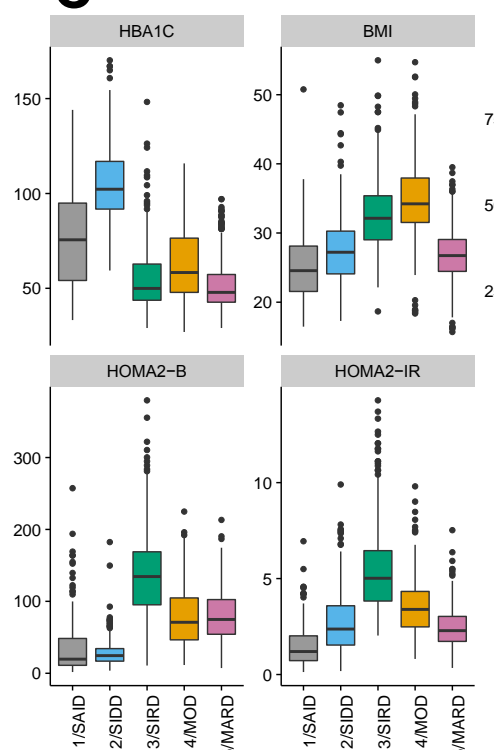

E
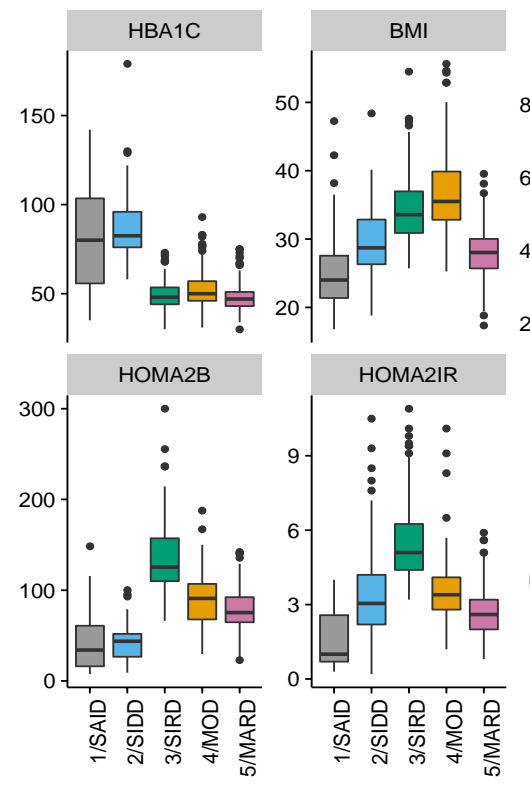
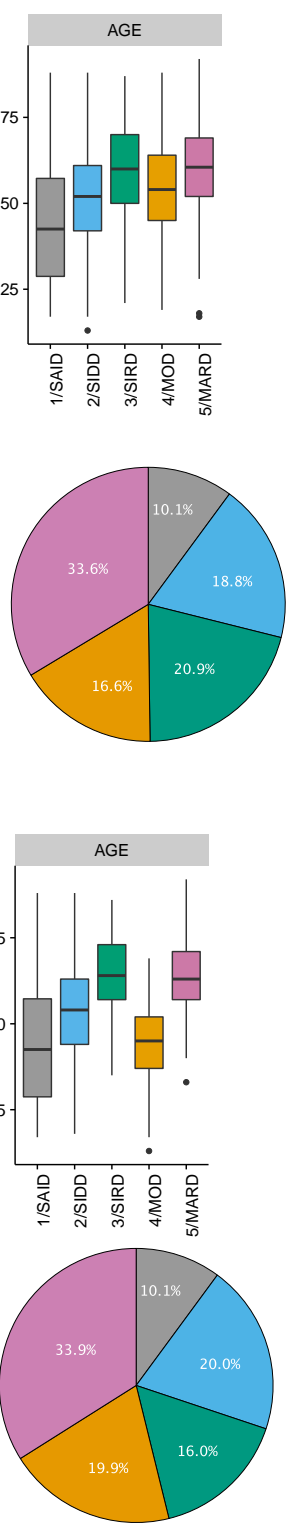
ill rights reserved. No reuse allowed without permission.
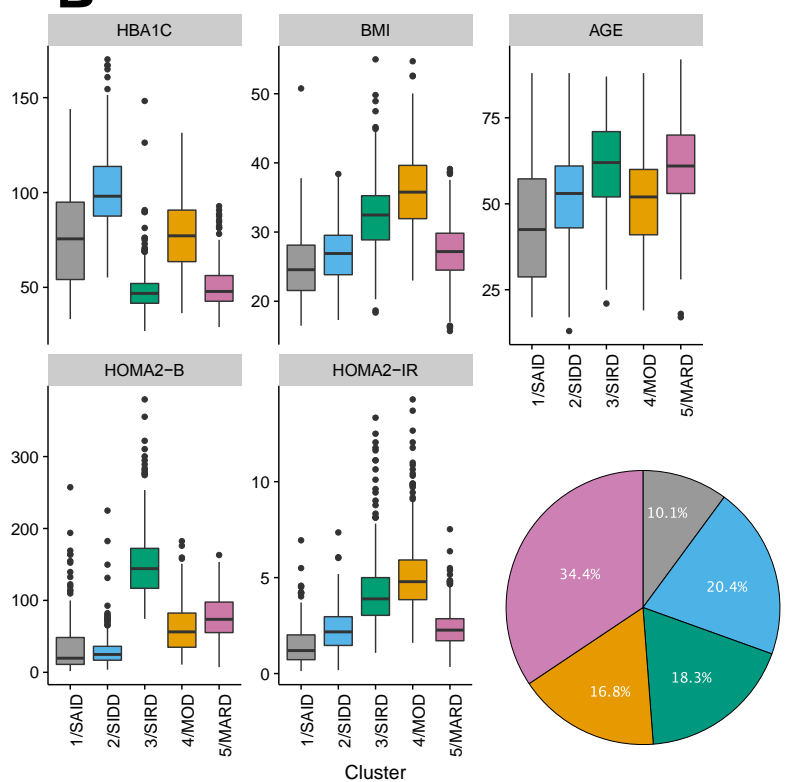

D

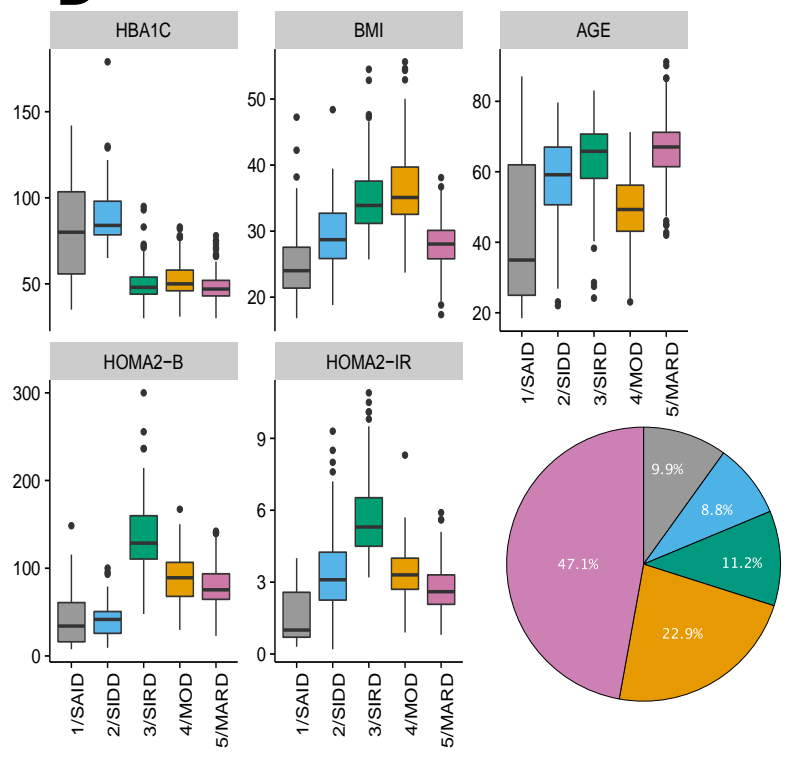

Figure S3. Replication of clustering in two independent Swedish cohorts, SDR and ANDIU.

Cluster distributions and characteristics in the Scania Diabetes Registry (SDR) using TwoStep (A), kmeans $(\mathrm{k}=4)$ clustering (B) and cluster assignment based on ANDIS cluster coordinates (C). Cluster distributions and characteristics in ANDIU using kmeans $(\mathrm{k}=4)$ clustering (D) and cluster assignment based on ANDIS cluster coordinates (E). 
A
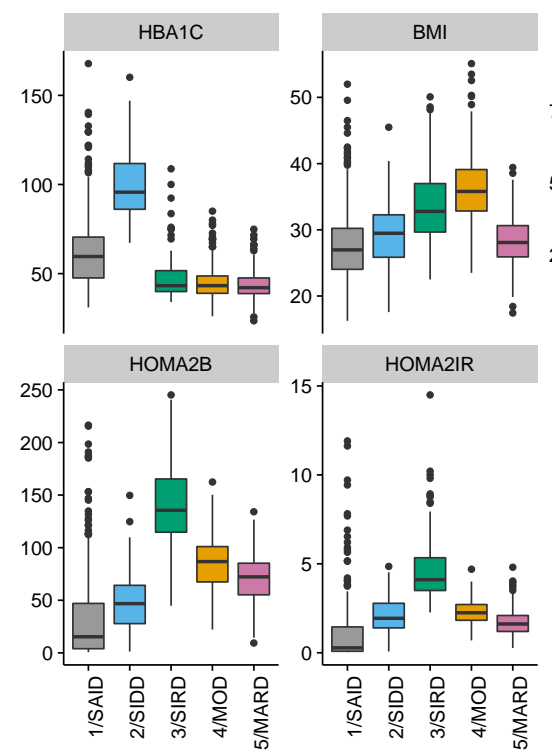

Cluster

C
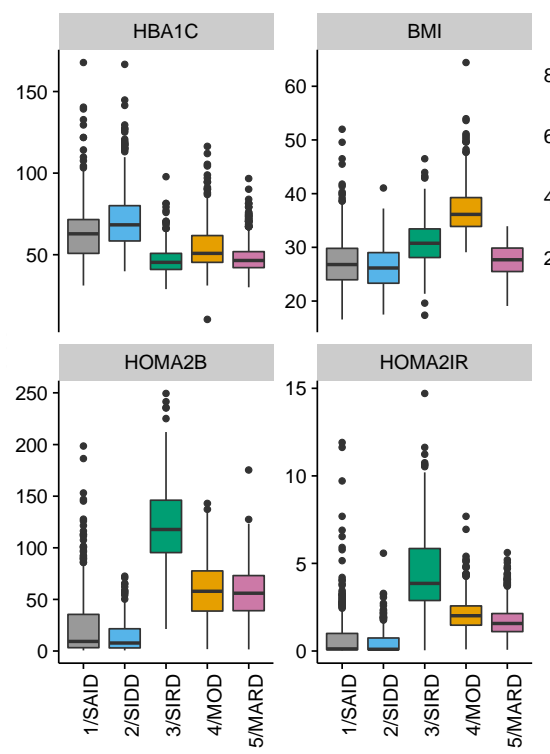

Cluster
B
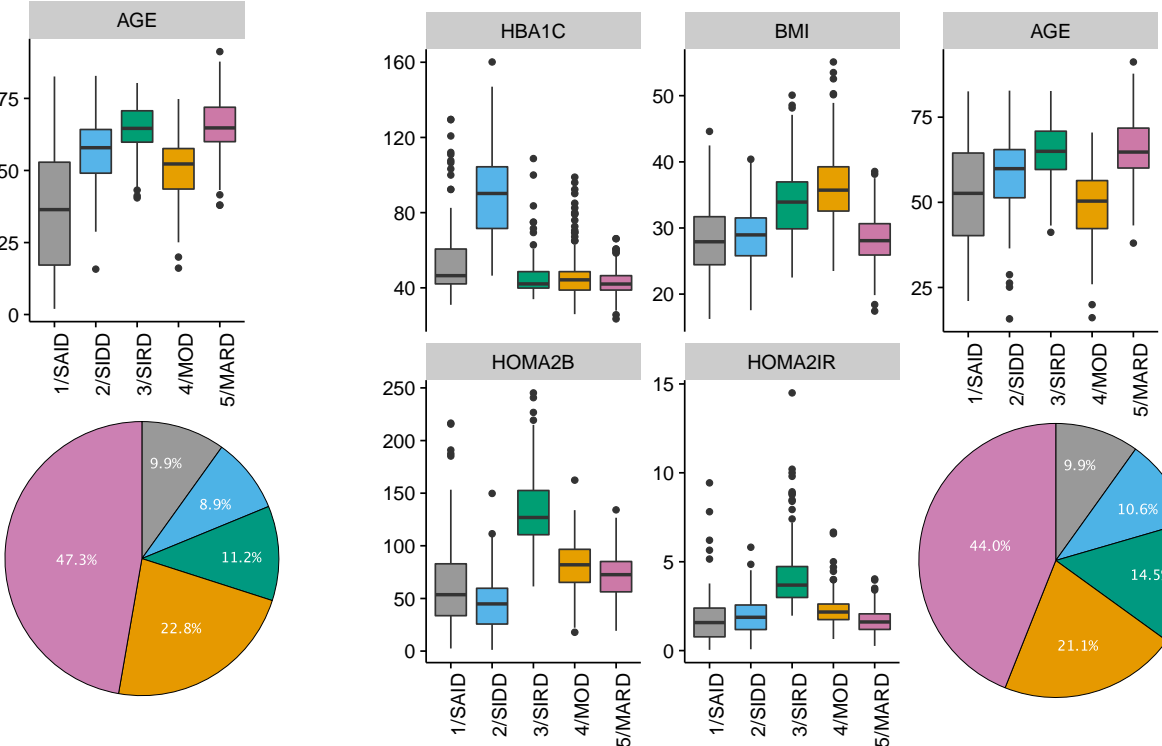

D
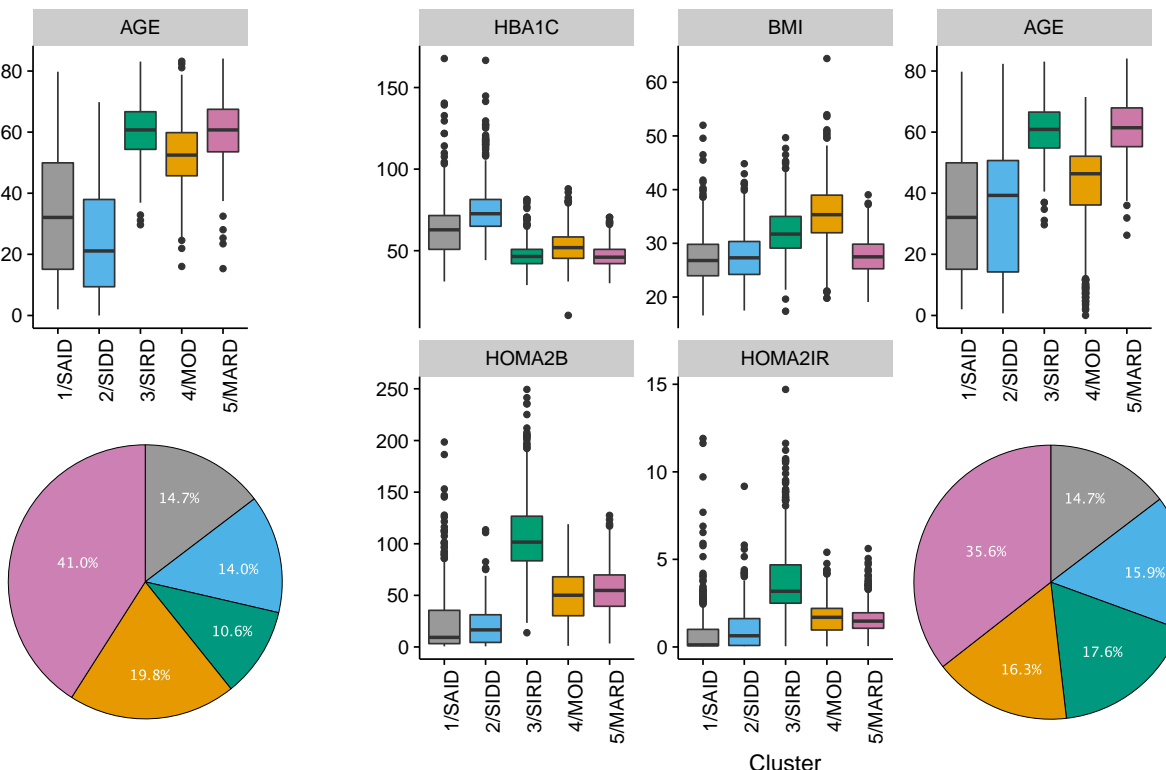

Cluster

Figure S4. Clustering in the Finnish DIREVA cohort comparing patients with newly diagnosed diabetes and longer duration.

Patient distribution in DIREVA in newly diagnosed (diabetes duration at sampling less than 2 years) using de novo kmeans clustering (A), and cluster assignment based on ANDIS cluster coordinates (B). Patient distribution in patients with longer duration at sampling (mean $10 \cdot 15 \pm 10 \cdot 34$ years) using de novo k-means clustering (C) and cluster assignment based on ANDIS cluster coordinates (D). 


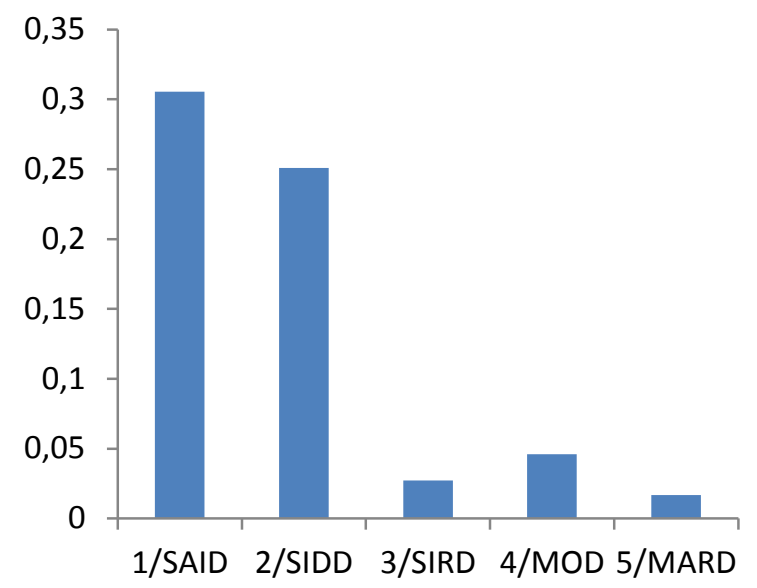

\section{Figure S5. Prevalence of ketoacidosis at diagnosis in ANDIS.}

Ketoacidosis at diagnosis was most common in clusters 1/SAID (30.5\%) and 2/SIDD (25.1\%), but rare in the others $(<5 \%)$.

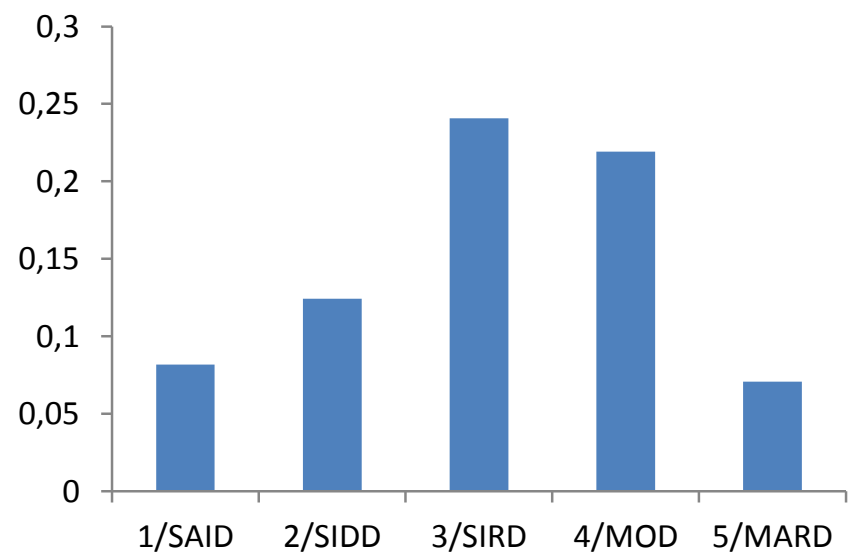

Figure S6. Prevalence of non-alcoholic fatty liver disease (NAFLD) in ANDIS estimated from ALT measurements.

A total of 11999 patients had at least one P-ALT measurement in the database of the Clinical Chemistry unit. Of them, $3739 \mathrm{had}$ at least two readings exceeding the upper reference values for the assays used $(>1 \cdot 1-1 \cdot 2 \mu \mathrm{kat} / \mathrm{L}$ for men and $>0 \cdot 7-0.85 \mu \mathrm{kat} / \mathrm{L}$ for women). Cluster 3/SIRD had the highest prevalence of NAFLD, defined as two pathological ALT measurements and $\mathrm{BMI}>28\left(\mathrm{OR} 3 \cdot 96[3 \cdot 27-4 \cdot 78], \mathrm{p}=5 \cdot 8 \times 10^{-46}\right.$ compared to MARD and OR $1 \cdot 56[1 \cdot 24-1 \cdot 95], \mathrm{p}=1 \cdot 4 \times 10^{-4}$ compared to MOD after adjustment for sex and age). 


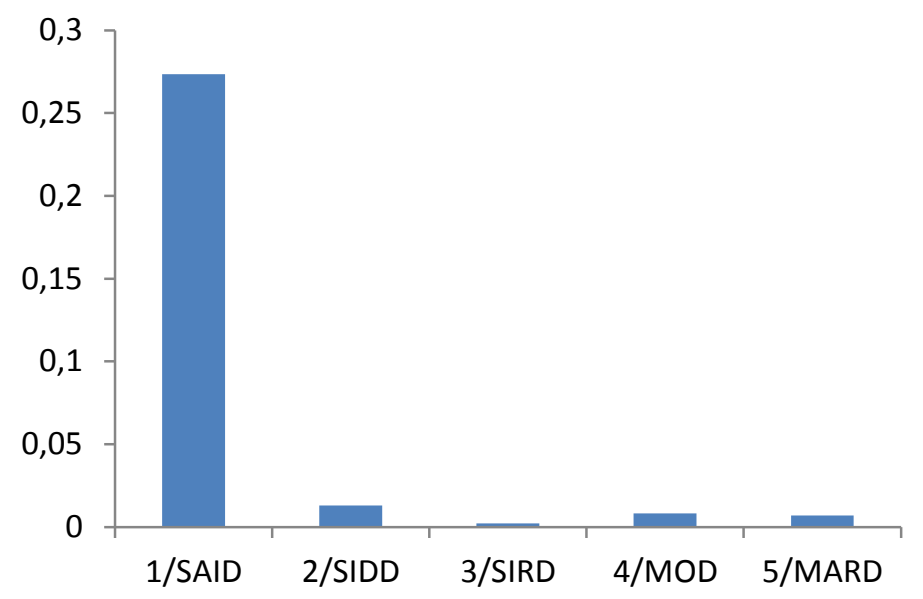

Figure S7. Auto-antibodies directed against zinc transporter 8A (ZnT8A).

ZnT8A auto-antibody positivity was mainly observed in patients from cluster 1/SAID (OR 52·74[26·89-103·45], $\left.\mathrm{p}=8 \cdot 6 \times 10^{-31}\right)$

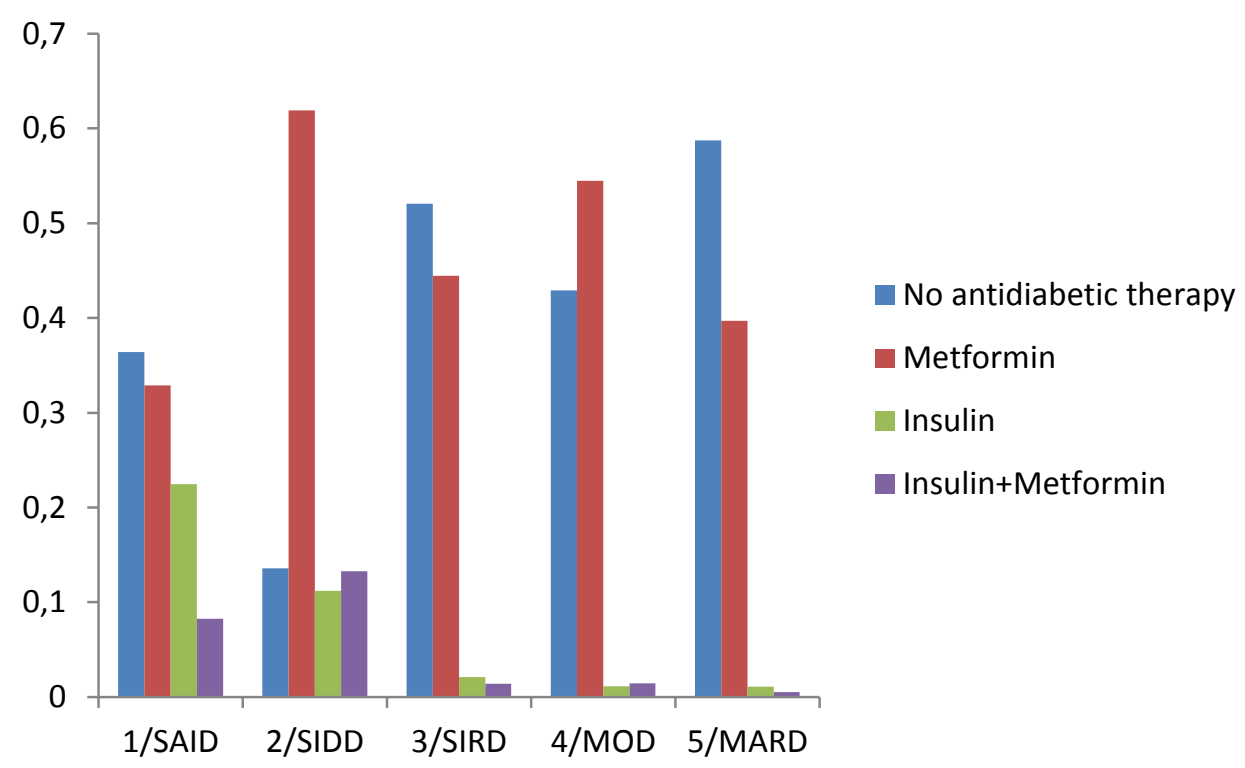

Figure S8. Antidiabetic medication (\%) at time of registration in ANDIS.

Figure S8 shows the frequency of use of metformin and/or insulin therapy at registration in ANDIS (at the time of measurement of plasma glucose and C-peptide) stratified by clustering. More patients in cluster 2/SIDD had been prescribed insulin and/or metformin than in clusters 3-5, reflecting the higher HbA1c at diagnosis. 
bioRxiv preprint doi: https://doi.org/10.1101/186387; this version posted September 8, 2017. The copyright holder for this preprint (which was not certified by peer review) is the author/funder. All rights reserved. No reuse allowed without permission.

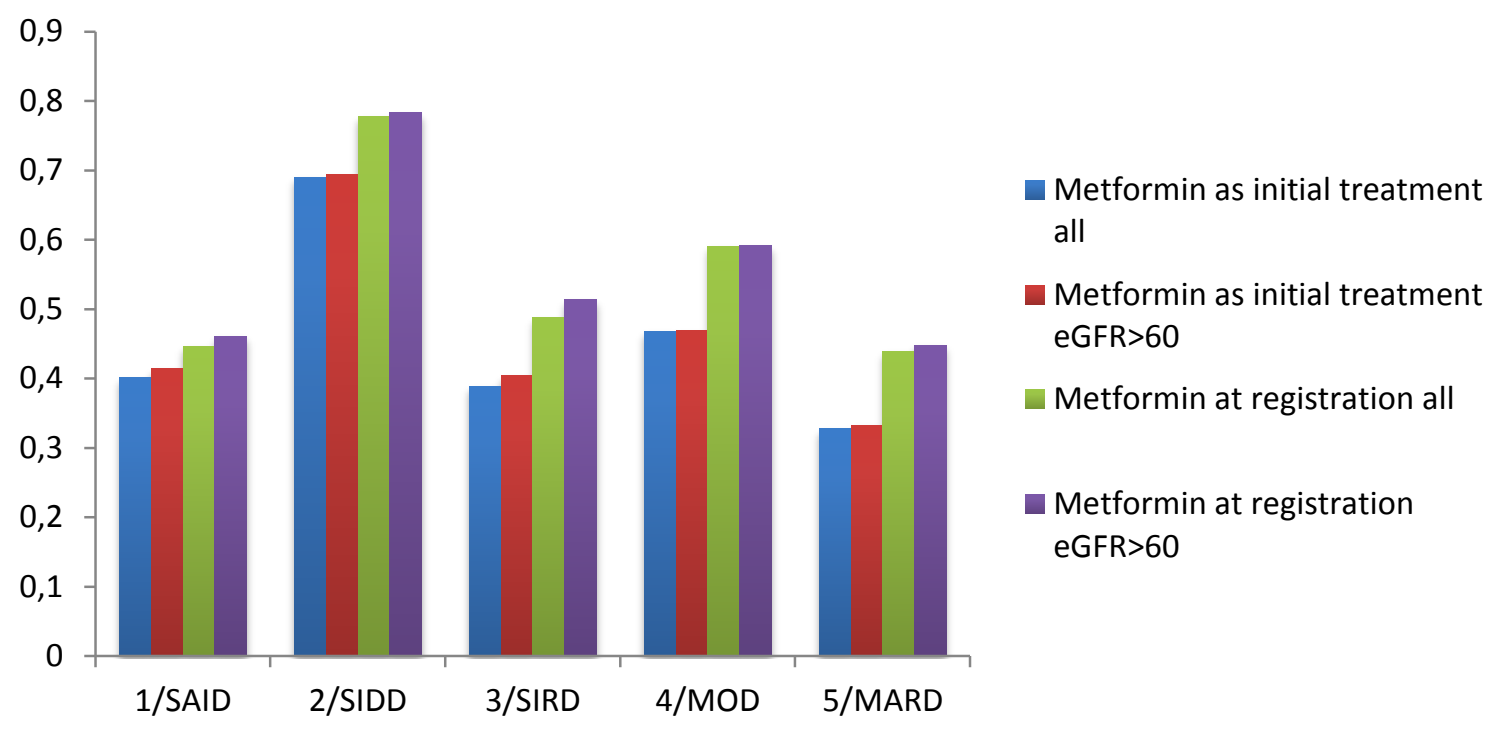

Figure S9. Metformin treatment (\%) by cluster in ANDIS

The percentage of patients in each cluster prescribed metformin as their first treatment after diagnosis (initial treatment), and percent of renally sufficient (eGFR $>60 \mathrm{~mL} / \mathrm{min} / 1 \cdot 73 \mathrm{~m}^{2}$ and ) patients on metformin at registration. This shows that the difference between clusters is not a result of discontinuation of metformin due to adverse effects or contra-indication of metformin in patients with kidney disease. 
A

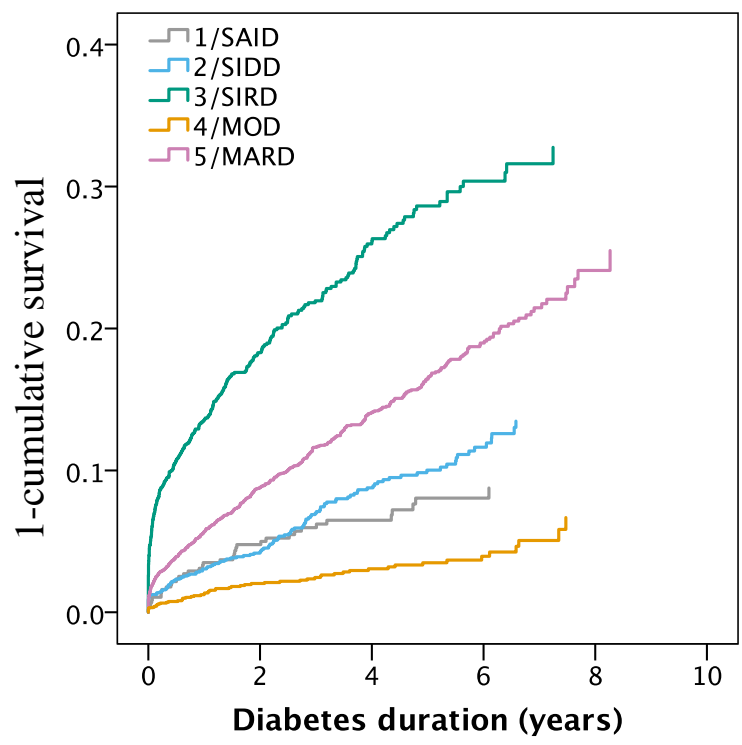

C

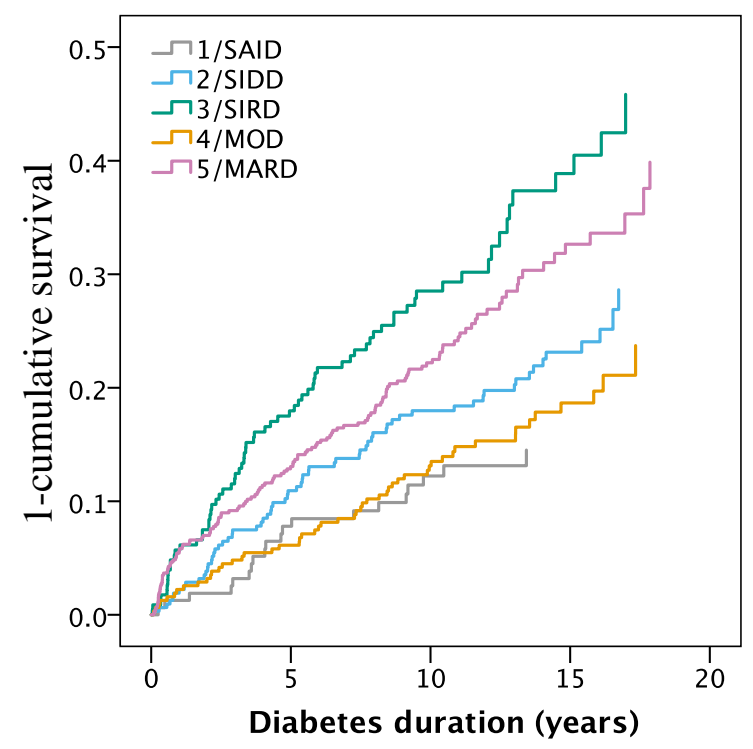

B

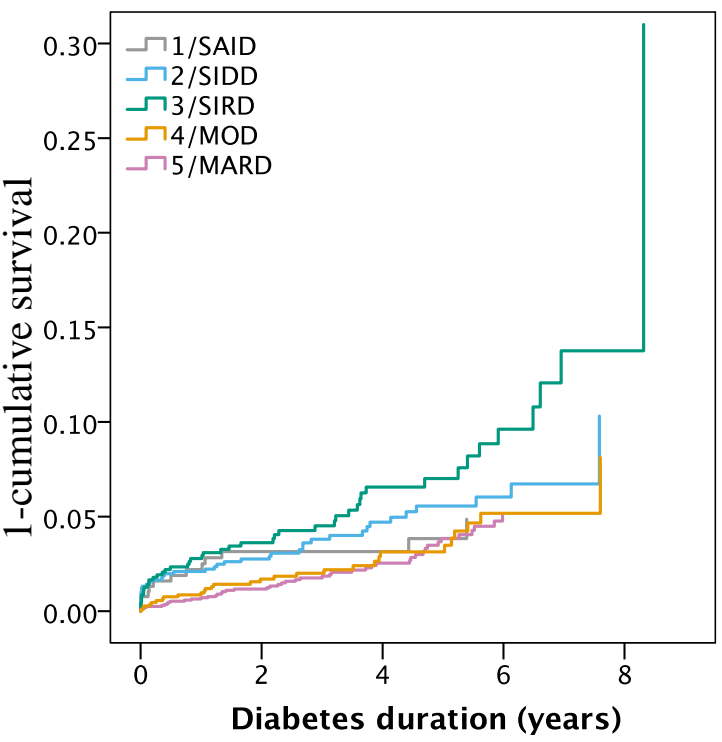

D

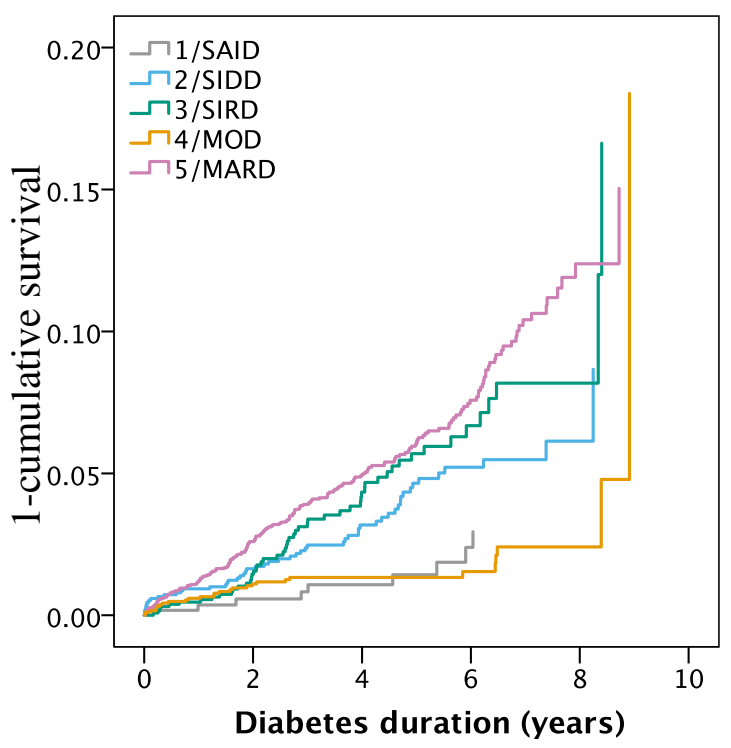

Figure S10. Risk of diabetic complications by cluster.

Cox regressions of diabetic complications for (A) CKD stage 3A (eGFR $<60 \mathrm{ml} / \mathrm{min}$ ) and macroalbuminuria (B) in ANDIS, coronary events (C) and stroke (D) in SDR. For statistics see Table S6 and S10. 
A

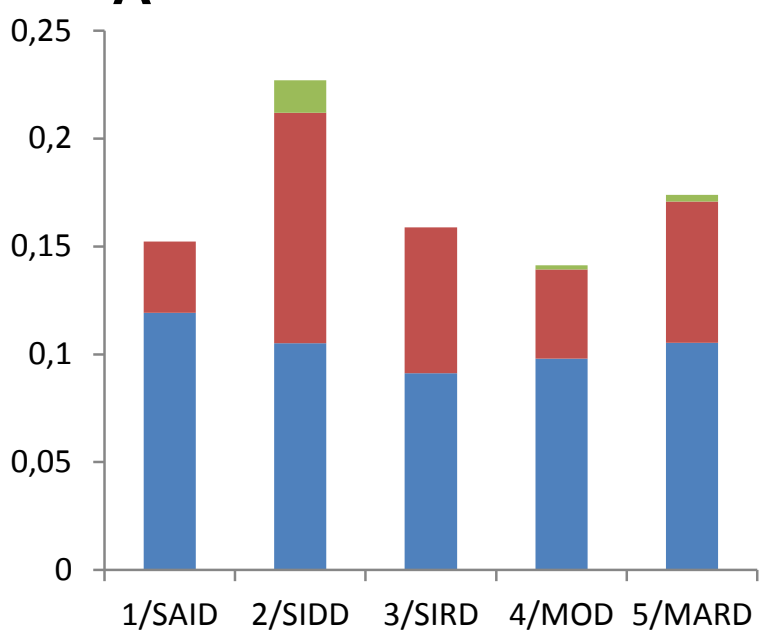

B

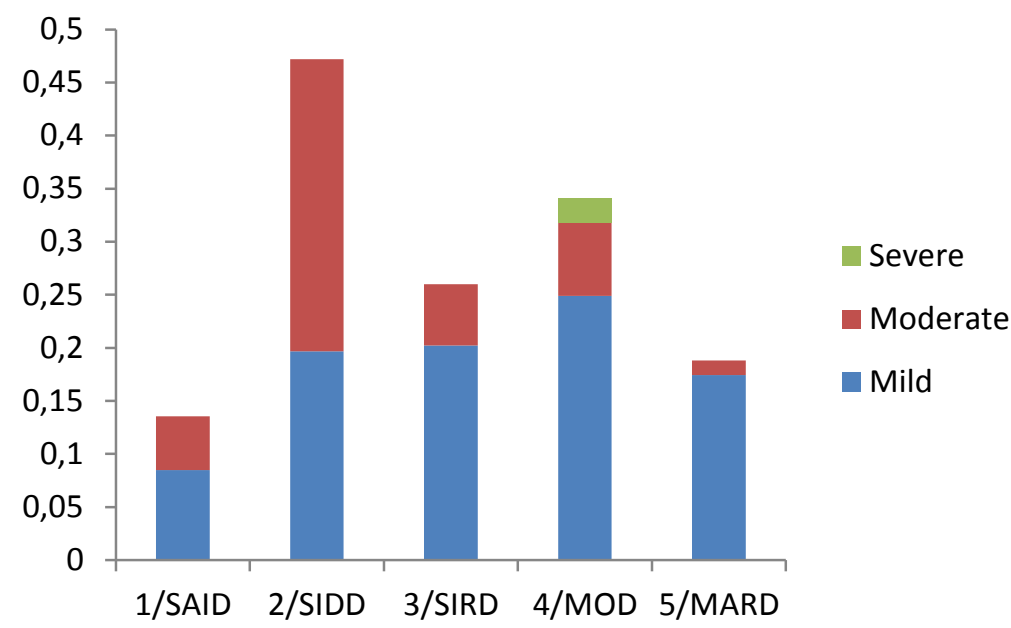

\section{Figure S11. Diabetic retinopathy (DR) at diagnosis}

Prevalence of different stages of diabetic retinopathy in (A) ANDIS and (B) ANDIU. In ANDIS DR risk was significantly higher in SIDD than in the reference cluster MARD (OR 1.6[1.3-1.9], $\mathrm{p}=9 \cdot 7 \times 10^{-7}$ ). In ANDIU DR risk

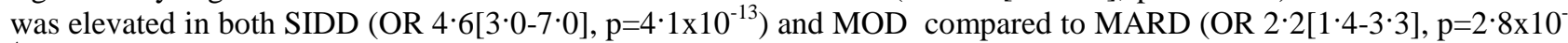
$\left.{ }^{4}\right)$.

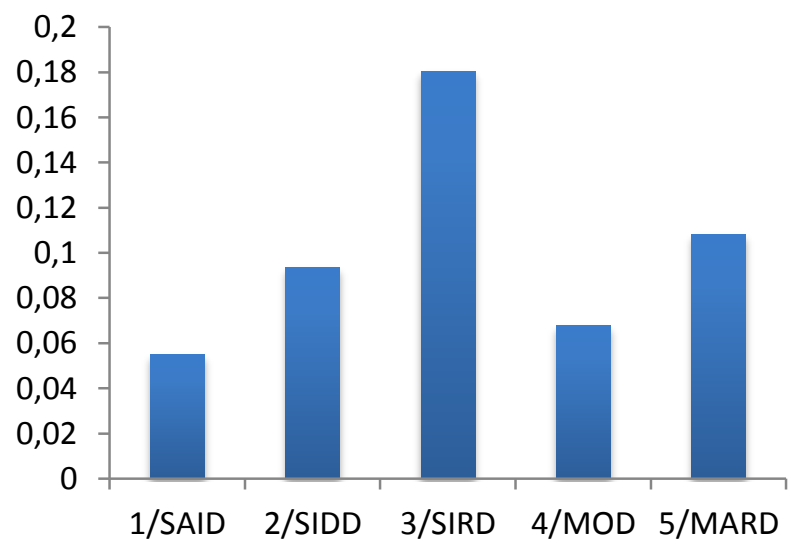

Figure S12. Prevalence of chronic kidney disease in DIREVA.

CKD (eGFR $<60 \mathrm{ml} / \mathrm{min}$ ) in DIREVA by clusters assigned based on ANDIS cluster coordinates. SIRD had increased risk of $\mathrm{CKD}\left(\mathrm{OR} 2 \cdot 02[1 \cdot 38-2 \cdot 96], \mathrm{p}=3 \cdot 4 \times 10^{-4}\right)$ after adjustment for age, sex and duration of diabetes. 

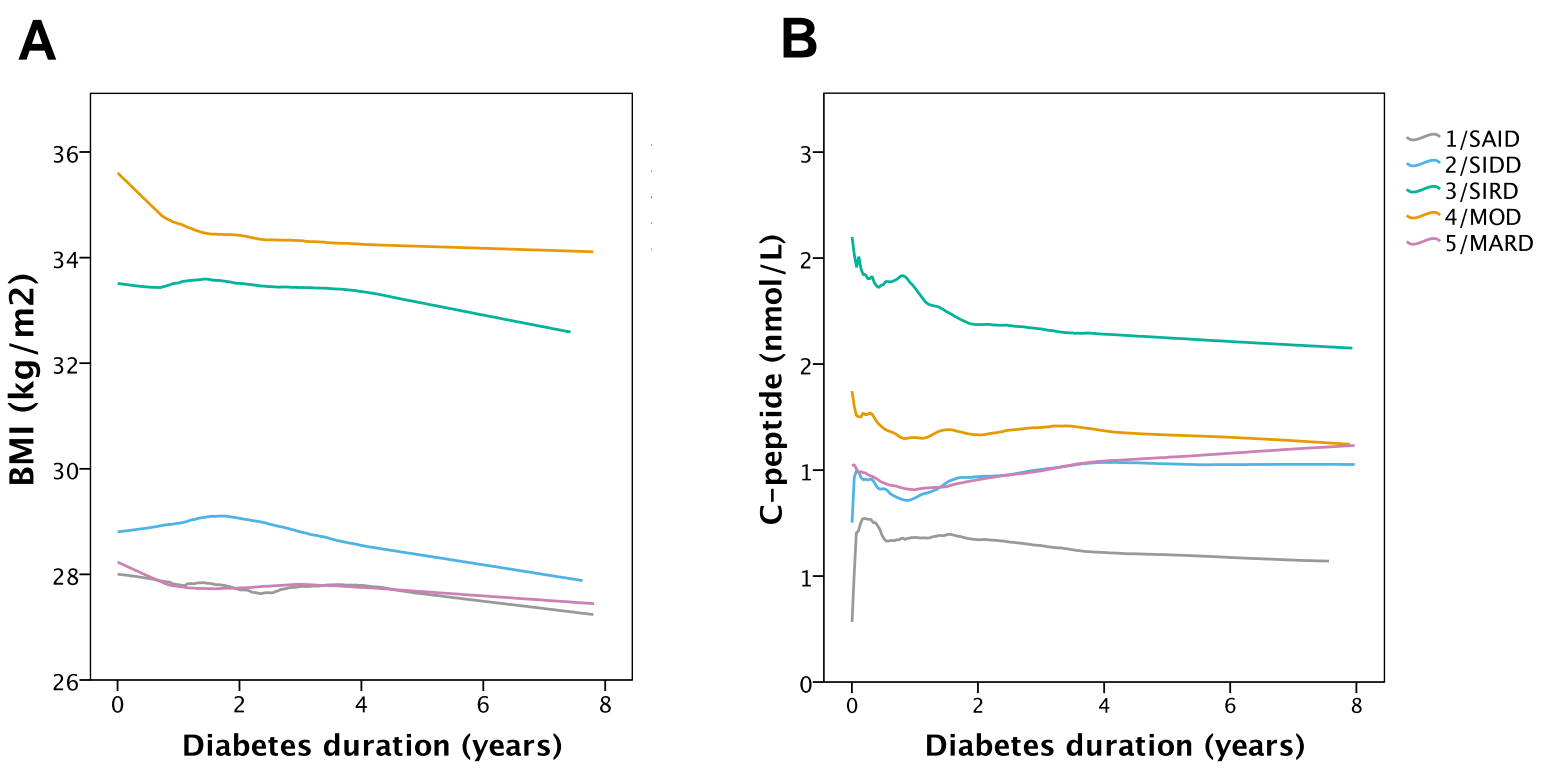

Figure S13. Change in cluster variables over time in ANDIS.

Figure S13 shows change in BMI(A) and C-peptide (B) during follow-up by cluster. 
bioRxiv preprint doi: https://doi.org/10.1101/186387; this version posted September 8, 2017. The copyright holder for this preprint (which was not certified by peer review) is the author/funder. All rights reserved. No reuse allowed without permission.

\section{Supplementary tables}

Table S1. Patient characteristics in ANDIS using the traditional classification*

\begin{tabular}{llll}
\hline & T1D & LADA & T2D \\
\hline N & 204 & 723 & $82 \cdot 7$ \\
\hline Frequency in total cohort, \% & $1 \cdot 4$ & $4 \cdot 9$ & 59.7 \\
Men, \% & $64 \cdot 7$ & $54 \cdot 1$ & $62 \cdot 32(24 \cdot 12)$ \\
\hline HBA1C at diagnosis, mmol/l & $107 \cdot 88(27 \cdot 06)$ & $73 \cdot 65(28 \cdot 26)$ & $30 \cdot 93(5 \cdot 72)$ \\
BMI, kg/m2 & $22 \cdot 02(3 \cdot 50)$ & $28 \cdot 77(6 \cdot 32)$ & $60 \cdot 93(12 \cdot 25)$ \\
\hline Age at diagnosis, years & $34 \cdot 03(13 \cdot 84)$ & $54 \cdot 86(12 \cdot 67)$ & $91 \cdot 95(48 \cdot 19)$ \\
\hline HOMA2B & $23 \cdot 50(20 \cdot 94)$ & $65 \cdot 46(46 \cdot 88)$ & $3 \cdot 41(2 \cdot 55)$ \\
\hline HOMA2IR & $0 \cdot 66(0 \cdot 35)$ & $2 \cdot 64(2 \cdot 08)$ & $9 \cdot 9$ \\
\hline Insulin at registration, \% & $96 \cdot 5$ & $33 \cdot 4$ & $52 \cdot 0$ \\
\hline Metformin at registration, \% & $10 \cdot 2$ & $43 \cdot 8$ & $11 \cdot 9$ \\
\hline History of gestational diabetes, \% of women & $3 \cdot 9$ & $16 \cdot 8$ & $23 \cdot 2$ \\
\hline Non-Scandinavian origin \% & $12 \cdot 5$ & & \\
\hline
\end{tabular}

*Only patients older than 18 at registration are included

Table S2. Patient characteristics in ANDIS using k-means clustering.

\begin{tabular}{|c|c|c|c|c|c|}
\hline & SAID & SIDD & SIRD & MOD & MARD \\
\hline $\mathbf{N}$ & 577 & 1575 & 1373 & 1942 & 3513 \\
\hline Frequency, \% & $6 \cdot 4$ & $17 \cdot 5$ & $15 \cdot 3$ & $21 \cdot 6$ & $39 \cdot 1$ \\
\hline Men, \% & $55 \cdot 1$ & $64 \cdot 8$ & $58 \cdot 8$ & $52 \cdot 1$ & $62 \cdot 0$ \\
\hline HBA1C at diagnosis, mmol/l & $80 \cdot 03(30 \cdot 84)$ & $101 \cdot 85(19 \cdot 26)$ & $54 \cdot 07(15 \cdot 46)$ & $57 \cdot 70(16 \cdot 07)$ & $50 \cdot 08(9 \cdot 85)$ \\
\hline BMI, kg/m2 & $27 \cdot 45(6 \cdot 44)$ & $28 \cdot 86(4 \cdot 77)$ & $33 \cdot 85(5 \cdot 24)$ & $35 \cdot 71(5 \cdot 43)$ & $27 \cdot 94(3 \cdot 44)$ \\
\hline Age at diagnosis, years & $50 \cdot 48(17 \cdot 93)$ & $56 \cdot 74(11 \cdot 14)$ & $65 \cdot 25(9 \cdot 34)$ & $48 \cdot 96(9 \cdot 54)$ & $67 \cdot 37(8 \cdot 55)$ \\
\hline HОМА2B & $56 \cdot 71(44 \cdot 65)$ & $47 \cdot 64(28 \cdot 93)$ & $150 \cdot 47(47 \cdot 20)$ & $95 \cdot 03(32 \cdot 45)$ & $86 \cdot 59(26 \cdot 37)$ \\
\hline HOMA2IR & $2 \cdot 16(1 \cdot 56)$ & $3 \cdot 18(1 \cdot 73)$ & $5 \cdot 54(2 \cdot 74)$ & $3 \cdot 35(1 \cdot 21)$ & $2 \cdot 55(0 \cdot 84)$ \\
\hline Insulin at registration, $\%$ & $41 \cdot 9$ & $29 \cdot 1$ & $3 \cdot 7$ & $3 \cdot 3$ & $1 \cdot 6$ \\
\hline Metformin at registration, $\%$ & $44 \cdot 7$ & $77 \cdot 8$ & $48 \cdot 8$ & $59 \cdot 1$ & $44 \cdot 0$ \\
\hline Family history of diabetes, $\%$ & 59 & 64 & 56 & 70 & 58 \\
\hline History of gestational diabetes, $\%$ of women & $10 \cdot 3$ & $7 \cdot 5$ & $4 \cdot 5$ & $21 \cdot 7$ & 5 \\
\hline Non-Scandinavian origin $\%$ & $15 \cdot 4$ & $26 \cdot 6$ & $15 \cdot 1$ & $32 \cdot 3$ & $16 \cdot 8$ \\
\hline
\end{tabular}


bioRxiv preprint doi: https://doi.org/10.1101/186387; this version posted September 8, 2017. The copyright holder for this preprint (which was not certified by peer review) is the author/funder. All rights reserved. No reuse allowed without permission.

Table S3. Cluster centres in ANDIS

\begin{tabular}{|c|c|c|c|c|c|c|}
\hline & Cluster & HBA1C & BMI & AGE & HOMA2B & HOMA2IR \\
\hline \multirow[t]{4}{*}{ Women } & 2/SIDD & $1 \cdot 8702613$ & $-0 \cdot 2415449$ & $-0 \cdot 1929637$ & $-0 \cdot 97446899$ & $0 \cdot 056469$ \\
\hline & 3/SIRD & $-0 \cdot 254848$ & $0 \cdot 5189057$ & $0 \cdot 3214557$ & $1 \cdot 35581907$ & $1 \cdot 1801933$ \\
\hline & 4/MOD & $-0 \cdot 3003478$ & $0 \cdot 6683606$ & -0.9388278 & $-0 \cdot 03556857$ & $-0 \cdot 1405151$ \\
\hline & 5/MARD & $-0 \cdot 4582762$ & -0.5854255 & 0.5980588 & $-0 \cdot 14552652$ & $-0 \cdot 4254893$ \\
\hline \multirow[t]{4}{*}{ Men } & 2/SIDD & $1 \cdot 52185804$ & $-0 \cdot 4284673$ & $-0 \cdot 4017103$ & -0.98397328 & $-0 \cdot 1630751$ \\
\hline & 3/SIRD & $-0 \cdot 39080167$ & 0.5396294 & $0 \cdot 4235841$ & $1 \cdot 29059153$ & $1 \cdot 1801031$ \\
\hline & 4/MOD & $-0 \cdot 06915764$ & $1 \cdot 0305317$ & $-1 \cdot 0157681$ & $0 \cdot 15742215$ & $0 \cdot 1343923$ \\
\hline & 5/MARD & -0.5367578 & $-0 \cdot 4776681$ & 0.5031031 & $-0 \cdot 09004338$ & $-0 \cdot 4233873$ \\
\hline
\end{tabular}

Table S4. Logistic regression analysis of risk factors for ketoacidosis at diagnosis in ANDIS

\begin{tabular}{lll}
\hline & OR(CI95\%)* & P \\
\hline HOMA2-B & $0 \cdot 66(0 \cdot 56-0 \cdot 77)$ & $1 \cdot 1 \times 10^{-7}$ \\
HOMA2-IR & $0 \cdot 95(0 \cdot 81-1 \cdot 12)$ & 0.55 \\
Age & $0 \cdot 65(0 \cdot 59-0 \cdot 72)$ & $1 \cdot 5 \times 10^{-17}$ \\
BMI & $0 \cdot 94(0 \cdot 84-1 \cdot 05)$ & $0 \cdot 28$ \\
HbA1c & $2 \cdot 73(2 \cdot 47-3 \cdot 03)$ & $2 \cdot 0 \times 10^{-82}$ \\
\hline
\end{tabular}

*OR are for $1 \mathrm{SD}$ change in variable. 
bioRxiv preprint doi: https://doi.org/10.1101/186387; this version posted September 8, 2017. The copyright holder for this preprint (which was not certified by peer review) is the author/funder. All rights reserved. No reuse allowed without permission.

Table S5. Cox regression analysis comparing antidiabetic treatments between clusters in ANDIS.

\begin{tabular}{|c|c|c|c|c|c|}
\hline & Events & Censored & $\%$ events & HR(CI95\%) & $\mathbf{P}$ \\
\hline \multicolumn{6}{|c|}{ Sustained insulin } \\
\hline 1/SAID & 260 & 194 & $57 \cdot 3$ & $26 \cdot 87(21 \cdot 17-34 \cdot 11)$ & $4 \cdot 3 \times 10^{-161}$ \\
\hline 2/SIDD & 381 & 908 & $29 \cdot 6$ & $10 \cdot 97(8 \cdot 73-13 \cdot 77)$ & $2 \cdot 5 \times 10^{-94}$ \\
\hline 3/SIRD & 73 & 1121 & $6 \cdot 1$ & $2 \cdot 03(1 \cdot 49-2 \cdot 76)$ & $7 \cdot 0 \times 10^{-6}$ \\
\hline 4/MOD & 97 & 1539 & $5 \cdot 9$ & $1 \cdot 90(1 \cdot 43-2 \cdot 53)$ & $1 \cdot 0 \times 10^{-5}$ \\
\hline 5/MARD & 92 & 2806 & $3 \cdot 2$ & 1 & - \\
\hline \multicolumn{6}{|l|}{ Metformin } \\
\hline 1/SAID & 267 & 177 & $60 \cdot 1$ & $0 \cdot 83(0 \cdot 73-0 \cdot 95)$ & $0 \cdot 005$ \\
\hline 2/SIDD & 1152 & 81 & $93 \cdot 4$ & $2 \cdot 56(2 \cdot 38-2 \cdot 76)$ & $2 \cdot 7 \times 10^{-138}$ \\
\hline 3/SIRD & 859 & 295 & $74 \cdot 4$ & $1 \cdot 17(1 \cdot 08-1 \cdot 27)$ & $8 \cdot 5 \times 10^{-5}$ \\
\hline 4/MOD & 1402 & 185 & $88 \cdot 3$ & $1 \cdot 67(1 \cdot 56-1-79)$ & $1 \cdot 8 \times 10^{-48}$ \\
\hline 5/MARD & 2007 & 826 & $70 \cdot 8$ & 1 & - \\
\hline \multicolumn{6}{|c|}{ Oral treatment other than metformin } \\
\hline 1/SAID & 36 & 419 & $7 \cdot 9$ & $1 \cdot 00(0 \cdot 70-1 \cdot 42)$ & $0 \cdot 99$ \\
\hline 2/SIDD & 339 & 950 & $26 \cdot 3$ & $3 \cdot 99(3 \cdot 36-4 \cdot 74)$ & $3 \cdot 0 \times 10^{-56}$ \\
\hline 3/SIRD & 162 & 1034 & $13 \cdot 5$ & $2 \cdot 10(1 \cdot 71-2 \cdot 58)$ & $1 \cdot 1 \times 10^{-12}$ \\
\hline 4/MOD & 264 & 1372 & $16 \cdot 1$ & $2 \cdot 36(1 \cdot 97-2 \cdot 83)$ & $2 \cdot 1 \times 10^{-20}$ \\
\hline 5/MARD & 212 & 2687 & $7 \cdot 3$ & 1 & - \\
\hline \multicolumn{6}{|c|}{ Reaching treatment goal } \\
\hline 1/SAID & 353 & 130 & $73 \cdot 1$ & $0 \cdot 60(0 \cdot 53-0 \cdot 67)$ & $9 \cdot 4 \times 10^{-19}$ \\
\hline 2/SIDD & 957 & 516 & $65 \cdot 0$ & $0 \cdot 46(0 \cdot 43-0 \cdot 50)$ & $1 \cdot 3 \times 10^{-84}$ \\
\hline 3/SIRD & 726 & 109 & $86 \cdot 9$ & $0 \cdot 90(0 \cdot 83-0 \cdot 98)$ & $0 \cdot 016$ \\
\hline 4/MOD & 1099 & 257 & $81 \cdot 0$ & $0 \cdot 77(0 \cdot 71-0 \cdot 83)$ & $5 \cdot 0 \times 10^{-12}$ \\
\hline 5/MARD & 1905 & 240 & $88 \cdot 8$ & 1 & - \\
\hline
\end{tabular}

The table information from the Swedish Drug Prescription Registry of patient's pick-up of medication from the pharmacy. Sustained insulin is defined as more than 6 months on insulin treatment. Reaching treatment goal is defined as the first time point after diagnosis the HbA1c is below $52 \mathrm{mmol} / \mathrm{mol}$. 
bioRxiv preprint doi: https://doi.org/10.1101/186387; this version posted September 8, 2017. The copyright holder for this preprint (which was not certified by peer review) is the author/funder. All rights reserved. No reuse allowed without permission.

Table S6. Cox regression analysis comparing risk of kidney complications in ANDIS

\begin{tabular}{|c|c|c|c|c|c|c|c|c|}
\hline & & Events & Censored & $\begin{array}{l}\text { Events } \\
(\%)\end{array}$ & $\operatorname{HR}(\operatorname{CI95\% })^{1}$ & $\mathbf{p}^{1}$ & $\underset{2}{\mathrm{HR}}(\mathrm{CI} 95 \%)$ & $\mathbf{p}^{2}$ \\
\hline \multirow[t]{5}{*}{ CKD 3A } & 1/SAID & 37 & 534 & $6 \cdot 5$ & $0.91(0 \cdot 65-1 \cdot 27)$ & 0.57 & $0 \cdot 86(0 \cdot 61-1 \cdot 20)$ & $0 \cdot 37$ \\
\hline & 2/SIDD & 123 & 1411 & $8 \cdot 0$ & $1 \cdot 34(1 \cdot 09-1 \cdot 64)$ & $0 \cdot 006$ & $1 \cdot 23(1 \cdot 00-1 \cdot 51)$ & $0 \cdot 06$ \\
\hline & 3/SIRD & 298 & 1037 & $22 \cdot 3$ & $2 \cdot 41(2 \cdot 08-2 \cdot 79)$ & $1 \cdot 4 \times 10^{-31}$ & $1 \cdot 56(1 \cdot 34-1 \cdot 82)$ & $6 \cdot 4 \times 10^{-9}$ \\
\hline & 4/MOD & 55 & 1828 & $2 \cdot 9$ & $1 \cdot 17(0 \cdot 86-1 \cdot 60)$ & $0 \cdot 31$ & $1 \cdot 06(0 \cdot 77-1 \cdot 44)$ & $0 \cdot 73$ \\
\hline & 5/MARD & 454 & 2950 & $13 \cdot 3$ & 1 & - & 1 & - \\
\hline \multirow[t]{5}{*}{ CKD 3B } & 1/SAID & 11 & 557 & $1 \cdot 9$ & $1 \cdot 01(0 \cdot 55-1 \cdot 87)$ & $0 \cdot 98$ & $0 \cdot 92(0 \cdot 49-1 \cdot 70)$ & $0 \cdot 78$ \\
\hline & 2/SIDD & 42 & 1492 & $2 \cdot 7$ & $1 \cdot 73(1 \cdot 21-2 \cdot 48)$ & $0 \cdot 003$ & $1 \cdot 21(0 \cdot 83-1 \cdot 76)$ & $0 \cdot 32$ \\
\hline & 3/SIRD & 118 & 1217 & $8 \cdot 8$ & $3 \cdot 34(2 \cdot 59-4 \cdot 30)$ & $8 \cdot 3 \times 10^{-21}$ & $1 \cdot 86(1 \cdot 44-2 \cdot 41)$ & $3 \cdot 0 \times 10^{-6}$ \\
\hline & 4/MOD & 19 & 1821 & $1 \cdot 0$ & $1 \cdot 73(1 \cdot 01-2 \cdot 96)$ & $0 \cdot 045$ & $1 \cdot 49(0 \cdot 86-2 \cdot 57)$ & $0 \cdot 15$ \\
\hline & 5/MARD & 128 & 3270 & $3 \cdot 8$ & 1 & - & 1 & - \\
\hline \multirow{5}{*}{$\begin{array}{l}\text { Macro- } \\
\text { albuminuria }\end{array}$} & 1/SAID & 13 & 379 & $3 \cdot 3$ & $1 \cdot 48(0 \cdot 80-2 \cdot 74)$ & $0 \cdot 21$ & $2 \cdot 52(1 \cdot 37-4 \cdot 79)$ & 0.005 \\
\hline & 2/SIDD & 41 & 970 & $4 \cdot 1$ & $1 \cdot 80(1 \cdot 19-2 \cdot 74)$ & $0 \cdot 006$ & $2 \cdot 71(1 \cdot 74-4 \cdot 20)$ & $9 \cdot 0 \times 10^{-6}$ \\
\hline & 3/SIRD & 46 & 770 & $5 \cdot 6$ & $2 \cdot 74(1 \cdot 82-4 \cdot 11)$ & $1 \cdot 0 \times 10^{-6}$ & $2 \cdot 45(1 \cdot 62-3 \cdot 71)$ & $2 \cdot 2 \times 10^{-5}$ \\
\hline & 4/MOD & 29 & 1077 & $2 \cdot 6$ & $1 \cdot 26(0 \cdot 79-2 \cdot 00)$ & $0 \cdot 34$ & $2 \cdot 19(1 \cdot 28-3 \cdot 75)$ & $0 \cdot 004$ \\
\hline & 5/MARD & 47 & 1964 & $2 \cdot 3$ & 1 & - & 1 & - \\
\hline \multirow[t]{5}{*}{ ESRD } & 1/SAID & 3 & 482 & $0 \cdot 6$ & $1 \cdot 16(0 \cdot 35-3 \cdot 84)$ & $0 \cdot 81$ & $1 \cdot 07(0 \cdot 33-3 \cdot 55)$ & $0 \cdot 91$ \\
\hline & 2/SIDD & 16 & 1438 & $1 \cdot 1$ & $2 \cdot 58(1 \cdot 36-4 \cdot 91)$ & $0 \cdot 004$ & $2 \cdot 68(1 \cdot 42-5 \cdot 07)$ & $0 \cdot 002$ \\
\hline & 3/SIRD & 25 & 1306 & 1.9 & $3 \cdot 12(1 \cdot 82-5 \cdot 36)$ & $3 \cdot 8 \times 10^{-5}$ & $2 \cdot 00(1 \cdot 15-3 \cdot 49)$ & $0 \cdot 015$ \\
\hline & 4/MOD & 8 & 1313 & $0 \cdot 6$ & $2 \cdot 37(0 \cdot 96-5 \cdot 83)$ & 0.06 & $2 \cdot 04(0 \cdot 82-5 \cdot 05)$ & $0 \cdot 12$ \\
\hline & 5/MARD & 28 & 3203 & 0.9 & 1 & - & 1 & - \\
\hline
\end{tabular}

${ }^{1}$ Cox regressions adjusted for sex and age at onset.

${ }^{2}$ Cox regression adjusted for sex, age at onset and first eGFR

CKD3A was defined as eGFR $<60 \mathrm{~mL} / \mathrm{min} / 1 \cdot 73 \mathrm{~m}^{2}$ and CKD3B as eGFR $<45 \mathrm{~mL} / \mathrm{min} / 1 \cdot 73 \mathrm{~m}^{2}$ for more than 90 days. End-stage renal disease (ESRD) was defined as at least one eGFR below $15 \mathrm{~mL} / \mathrm{min} / 1 \cdot 73 \mathrm{~m}^{2}$. Diabetic kidney disease (DKD) was defined as either ESRD or macroalbuminuria defined as at least two out of three consecutive visits with albumin excretion rate $($ AER) $\geq 200 \mu \mathrm{g} / \mathrm{min}$ or AER $\geq 300 \mathrm{mg} / 24 \mathrm{~h}$ or albumin-creatinine ratio (ACR) $\geq 25 / 35 \mathrm{mg} / \mathrm{mmol}$ for men/women. Median duration at first eGFR 53(IQR 1-286) days. 
bioRxiv preprint doi: https://doi.org/10.1101/186387; this version posted September 8, 2017. The copyright holder for this preprint (which was not certified by peer review) is the author/funder. All rights reserved. No reuse allowed without permission.

Table S7. Cox regression analysis comparing risk of cardiovascular disease between clusters in ANDIS

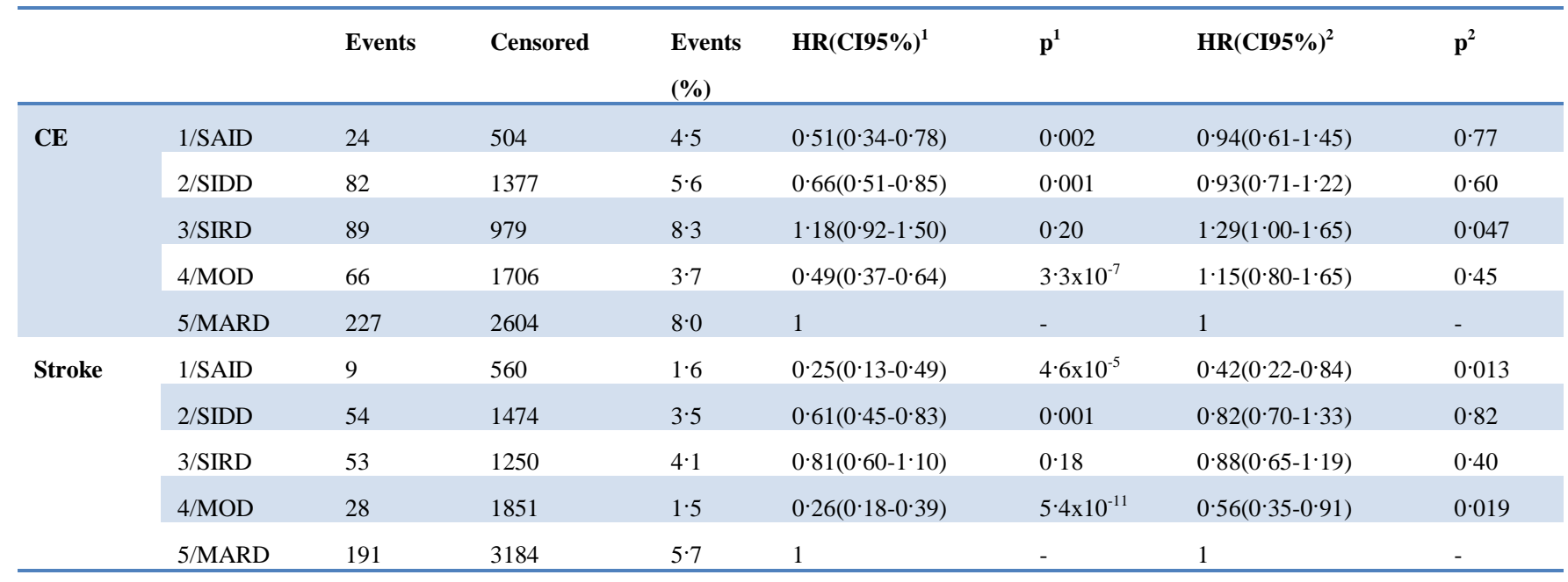

${ }^{1}$ Cox regression adjusted for sex.

${ }^{2}$ Cox regressions adjusted for sex and age at onset.

Coronary events (CE) were defined by ICD-10 codes I21, I252, I20, I251, I253, I254, I255, I256, I257, I258, I259.

Stroke was defined by ICD-10 codes I60, I61, I63 and I64. 
bioRxiv preprint doi: https://doi.org/10.1101/186387; this version posted September 8, 2017. The copyright holder for this preprint (which was not certified by peer review) is the author/funder. All rights reserved. No reuse allowed without permission.

Table S8. Cox regression analysis comparing risk of kidney complications between clusters in SDR

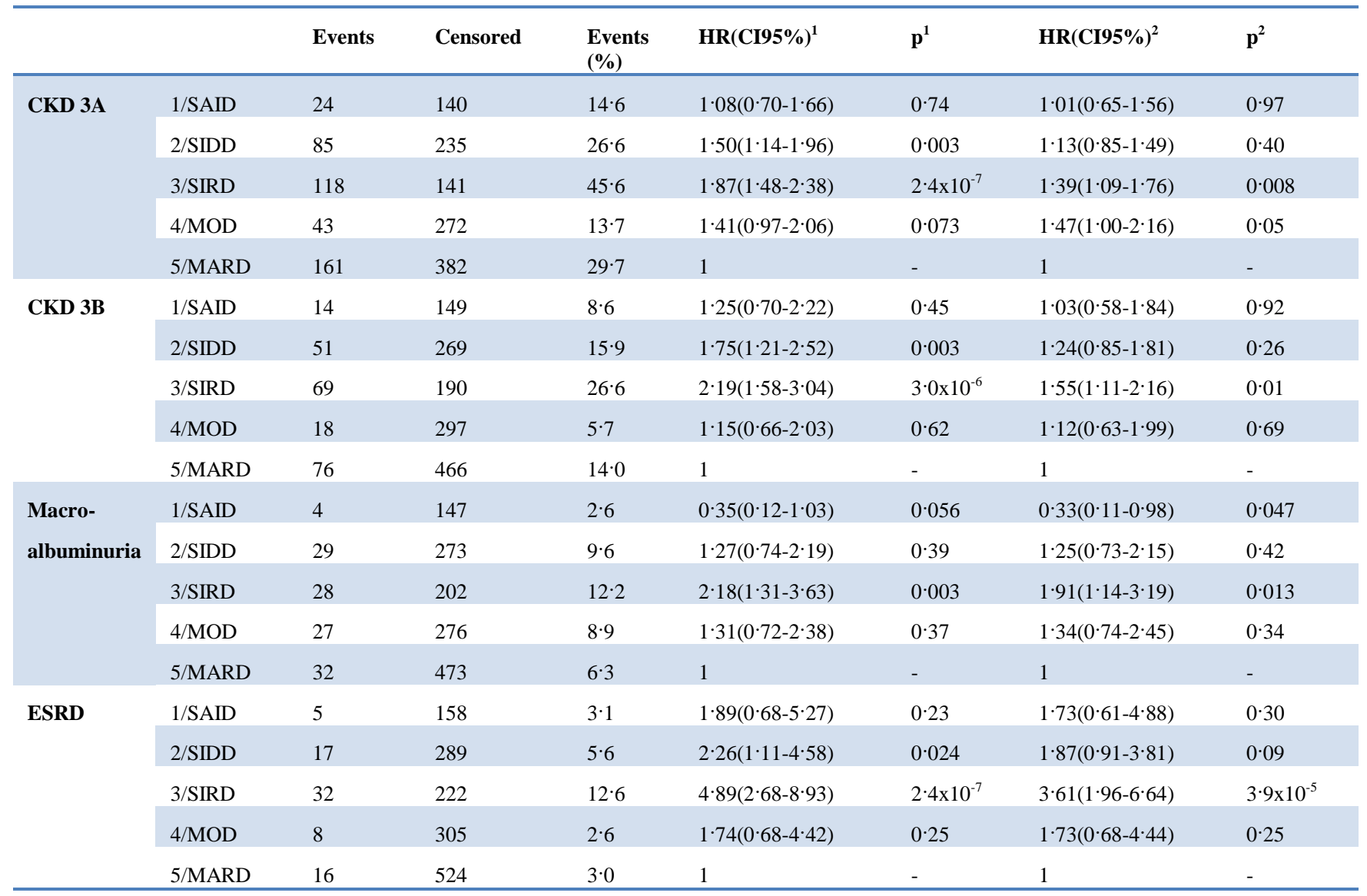

${ }^{1}$ Cox regressions adjusted for sex and age at onset.

${ }^{2}$ Cox regression adjusted for sex, age at onset and first eGFR.

CKD3A was defined as eGFR $<60 \mathrm{~mL} / \mathrm{min} / 1 \cdot 73 \mathrm{~m}^{2}$ and (CKD 3B) as eGFR $<45 \mathrm{~mL} / \mathrm{min} / 1 \cdot 73 \mathrm{~m}^{2}$ for more than 90 days. End-stage renal disease (ESRD) was defined as at least one eGFR below $15 \mathrm{~mL} / \mathrm{min} / 1 \cdot 73 \mathrm{~m}^{2}$. Diabetic kidney disease (DKD) was defined as either ESRD or macroalbuminuria defined as at least two out of three consecutive visits with albumin excretion rate (AER) $\geq 200 \mu \mathrm{g} / \mathrm{min}$ or $\mathrm{AER} \geq 300 \mathrm{mg} / 24 \mathrm{~h}$ or albumin-creatinine ratio (ACR) $\geq 25 / 35$ $\mathrm{mg} / \mathrm{mmol}$ for men/women.

Median duration at first $\mathrm{eGFR}=100(\mathrm{IQR} 54-173)$ days. 
bioRxiv preprint doi: https://doi.org/10.1101/186387; this version posted September 8, 2017. The copyright holder for this preprint (which was not certified by peer review) is the author/funder. All rights reserved. No reuse allowed without permission.

Table S9. Cox regression analysis comparing risk of diabetic retinopathy between clusters in SDR

\begin{tabular}{lllllllll}
\hline & Events & Censored & $\begin{array}{c}\text { Events } \\
(\%)\end{array}$ & HR(CI95\%) & p $^{\mathbf{1}}$ & HR(CI95\%) $^{\mathbf{2}}$ & $\mathbf{p}^{\mathbf{2}}$ \\
\hline \multirow{2}{*}{ DR } & 1/SAID & 85 & 57 & $59 \cdot 9$ & $0 \cdot 82(0 \cdot 62-1 \cdot 07)$ & $0 \cdot 82$ & $1 \cdot 00(0 \cdot 71-1 \cdot 41)$ & $0 \cdot 99$ \\
& 2/SIDD & 169 & 96 & $63 \cdot 8$ & $1 \cdot 25(1 \cdot 01-1 \cdot 55)$ & $0 \cdot 044$ & $1 \cdot 49(1 \cdot 17-1 \cdot 89)$ & $0 \cdot 001$ \\
& 3/SIRD & 62 & 117 & $34 \cdot 6$ & $0 \cdot 72(0 \cdot 54-0 \cdot 97)$ & $0 \cdot 029$ & $0 \cdot 74(0 \cdot 55-1 \cdot 00)$ & $0 \cdot 048$ \\
& 4/MOD & 134 & 139 & $49 \cdot 1$ & $0 \cdot 95(0 \cdot 75-1 \cdot 19)$ & $0 \cdot 64$ & $1 \cdot 28(0 \cdot 94-1 \cdot 75)$ & $0 \cdot 11$ \\
& 5/MARD & 165 & 252 & $39 \cdot 6$ & 1 & - & 1 & - \\
\hline
\end{tabular}

${ }^{1}$ Cox regressions adjusted for sex.

${ }^{2}$ Cox regression adjusted for sex and age at onset.

Table S10. Cox regression analysis comparing risk of cardiovascular disease between clusters in SDR

\begin{tabular}{|c|c|c|c|c|c|c|c|c|}
\hline & & Events & Censored & $\begin{array}{l}\text { Events } \\
(\%)\end{array}$ & $\operatorname{HR}(C I 95 \%)^{1}$ & $\mathbf{p}^{1}$ & $\operatorname{HR}(\mathrm{CI} 95 \%)^{2}$ & $\mathbf{p}^{2}$ \\
\hline \multirow[t]{5}{*}{ CE } & 1/SAID & 20 & 138 & $12 \cdot 7$ & $0 \cdot 43(0 \cdot 27-0 \cdot 69)$ & $4 \cdot 6 \times 10^{-4}$ & $0 \cdot 98(0 \cdot 60-1 \cdot 63)$ & $0 \cdot 98$ \\
\hline & 2/SIDD & 66 & 248 & $21 \cdot 0$ & $0 \cdot 71(0 \cdot 53-0 \cdot 95)$ & $0 \cdot 023$ & $1 \cdot 16(0 \cdot 84-1 \cdot 59)$ & $0 \cdot 37$ \\
\hline & 3/SIRD & 72 & 156 & $31 \cdot 6$ & $1 \cdot 31(0 \cdot 99-1 \cdot 75)$ & $0 \cdot 064$ & $1 \cdot 26(0 \cdot 89-1 \cdot 78)$ & $0 \cdot 19$ \\
\hline & 4/MOD & 52 & 262 & $16 \cdot 6$ & $0 \cdot 56(0 \cdot 41-0 \cdot 78)$ & $0 \cdot 001$ & $1 \cdot 43(0 \cdot 83-2 \cdot 45)$ & $0 \cdot 20$ \\
\hline & 5/MARD & 132 & 384 & $25 \cdot 6$ & 1 & - & 1 & - \\
\hline \multirow[t]{5}{*}{ Stroke } & $1 /$ SAID & 7 & 141 & $4 \cdot 7$ & $0 \cdot 33(0 \cdot 15-0 \cdot 72)$ & $0 \cdot 005$ & $0 \cdot 72(0 \cdot 32-1 \cdot 63$ & $0 \cdot 43$ \\
\hline & 2/SIDD & 17 & 300 & $5 \cdot 4$ & $0 \cdot 42(0 \cdot 24-0 \cdot 72)$ & $0 \cdot 002$ & $0 \cdot 68(0 \cdot 39-1 \cdot 20)$ & $0 \cdot 19$ \\
\hline & 3/SIRD & 19 & 221 & $7 \cdot 9$ & $0 \cdot 74(0 \cdot 44-1 \cdot 25)$ & $0 \cdot 26$ & $0 \cdot 76(0 \cdot 45-1 \cdot 28)$ & $0 \cdot 30$ \\
\hline & $4 / \mathrm{MOD}$ & 14 & 285 & $4 \cdot 7$ & $0 \cdot 32(0 \cdot 18-0 \cdot 57)$ & $1 \cdot 4 \times 10^{-4}$ & $0 \cdot 92(0 \cdot 44-1 \cdot 91)$ & $0 \cdot 81$ \\
\hline & 5/MARD & 56 & 484 & $10 \cdot 4$ & 1 & - & 1 & - \\
\hline
\end{tabular}

${ }^{1}$ Cox regression adjusted for sex.

${ }^{2}$ Cox regressions adjusted for sex and age at onset.

Coronary events (CE) were defined by ICD-10 codes I21, I252, I20, I251, I253, I254, I255, I256, I257, I258, I259.

Stroke was defined by ICD-10 codes I60, I61, I63 and I64. 
Table S11. Strongest genetic associations with specific ANDIS clusters (reaching $\mathbf{p}<0.01$ )

\begin{tabular}{|c|c|c|c|c|c|c|c|c|c|c|c|c|}
\hline SNP & Candidate gene & & SAID & & SIDD & & SIRD & & MOD & & MARD & \\
\hline & & & $\mathrm{N}=313$ & & $\mathrm{~N}=676$ & & $\mathrm{~N}=603$ & & $\mathrm{~N}=727$ & & $\mathrm{~N}=1341$ & \\
\hline & & MAF & OR & $P$ & OR & $P$ & OR & $P$ & OR & $\mathrm{P}$ & OR & $P$ \\
\hline rs 2854275 & HLA_DQB1 & $0 \cdot 13$ & $2 \cdot 05(1 \cdot 69-2 \cdot 56)$ & $5 \cdot 7 \times 10^{-10}$ & $0 \cdot 82(0 \cdot 66-1 \cdot 00)$ & $0 \cdot 078$ & $0 \cdot 97(0 \cdot 79-1 \cdot 19)$ & $0 \cdot 90$ & $1 \cdot 11(0 \cdot 92-1 \cdot 33)$ & $0 \cdot 27$ & $0 \cdot 87(0 \cdot 76-1 \cdot 01)$ & $0 \cdot 15$ \\
\hline rs6467136 & GCC1-PAX4 & $0 \cdot 46$ & $1 \cdot 42(1 \cdot 19-1 \cdot 69)$ & $7 \cdot 8 \times 10^{-5}$ & $1 \cdot 17(1 \cdot 04-1 \cdot 32)$ & $0 \cdot 022$ & $1 \cdot 06(0 \cdot 94-1 \cdot 21)$ & $0 \cdot 35$ & $1 \cdot 17(1 \cdot 04-1 \cdot 32)$ & $0 \cdot 013$ & $1 \cdot 27(1 \cdot 16-1 \cdot 39)$ & $4 \cdot 2 \times 10^{-7}$ \\
\hline rs7578326 & IRS1 & 0.36 & $0 \cdot 78(0 \cdot 65-0 \cdot 93)$ & $0 \cdot 0059$ & $0 \cdot 99(0 \cdot 87-1 \cdot 11)$ & 0.59 & $0 \cdot 94(0 \cdot 83-1 \cdot 11)$ & $0 \cdot 36$ & $1 \cdot 06(0 \cdot 94-1 \cdot 20)$ & $0 \cdot 42$ & $0 \cdot 94(0 \cdot 86-1 \cdot 03)$ & $0 \cdot 14$ \\
\hline rs8090011 & LAMA1 & $0 \cdot 37$ & $1 \cdot 25(1 \cdot 06-1 \cdot 48)$ & $0 \cdot 0069$ & $1 \cdot 12(0 \cdot 99-1 \cdot 23)$ & 0.053 & $1 \cdot 08(0 \cdot 95-1 \cdot 23)$ & $0 \cdot 15$ & $1 \cdot 11(0 \cdot 98-1 \cdot 25)$ & $0 \cdot 065$ & $1 \cdot 05(0 \cdot 96-1 \cdot 15)$ & $0 \cdot 17$ \\
\hline rs10010131 & WFS1 & $0 \cdot 43$ & $1 \cdot 28(1 \cdot 07-1 \cdot 53)$ & $0 \cdot 007$ & $1 \cdot 18(1 \cdot 04-1 \cdot 34)$ & $0 \cdot 018$ & $1 \cdot 07(0 \cdot 94-1 \cdot 22)$ & $0 \cdot 36$ & $1 \cdot 25(1 \cdot 11-1 \cdot 42)$ & $0 \cdot 00063$ & $1 \cdot 14(1 \cdot 04-1 \cdot 25)$ & $0 \cdot 0046$ \\
\hline rs7903146 & TCF7L2 & $0 \cdot 26$ & $1 \cdot 17(0 \cdot 97-1 \cdot 40)$ & $0 \cdot 077$ & $1 \cdot 51(1 \cdot 33-1 \cdot 71)$ & $2 \cdot 8 \times 10^{-10}$ & $1 \cdot 00(0 \cdot 87-1 \cdot 15)$ & $0 \cdot 86$ & $1 \cdot 38(1 \cdot 21-1 \cdot 56)$ & $5 \cdot 7 \times 10^{-7}$ & $1 \cdot 41(1 \cdot 28-1 \cdot 55)$ & $1 \cdot 1 \times 10^{-12}$ \\
\hline rs10401969 & TM6SF2 & $0 \cdot 09$ & $0 \cdot 75(0 \cdot 58-0 \cdot 97)$ & $0 \cdot 038$ & $0 \cdot 69(0 \cdot 58-0 \cdot 83)$ & $0 \cdot 00021$ & $0 \cdot 62(0 \cdot 52-0 \cdot 75)$ & $3 \cdot 1 \times 10^{-6}$ & $0 \cdot 89(0 \cdot 73-1 \cdot 07)$ & $0 \cdot 26$ & $0 \cdot 77(0 \cdot 67-0 \cdot 89)$ & $0 \cdot 00046$ \\
\hline rs4402960 & IGF2BP2 & $0 \cdot 29$ & $1 \cdot 04(0 \cdot 87-1 \cdot 24)$ & $0 \cdot 501$ & $1 \cdot 23(1 \cdot 08-1 \cdot 40)$ & $0 \cdot 00020$ & $1 \cdot 01(0 \cdot 88-1 \cdot 16)$ & 0.53 & $1 \cdot 04(0 \cdot 92-1 \cdot 18)$ & $0 \cdot 31$ & $1 \cdot 22(1 \cdot 11-1 \cdot 33)$ & $2 \cdot 1 \times 10^{-6}$ \\
\hline rs10811661 & CDKN2B & $0 \cdot 15$ & $0 \cdot 87(0 \cdot 70-1 \cdot 08)$ & $0 \cdot 242$ & $1 \cdot 33(1 \cdot 11-1 \cdot 59)$ & $0 \cdot 0014$ & $0 \cdot 98(0 \cdot 83-1 \cdot 17)$ & $0 \cdot 85$ & $0 \cdot 99(0 \cdot 84-1 \cdot 16)$ & 0.92 & $1 \cdot 18(1 \cdot 04-1 \cdot 33)$ & $0 \cdot 0054$ \\
\hline rs243088 & BCL11A & $0 \cdot 47$ & $1 \cdot 23(1 \cdot 04-1 \cdot 45)$ & $0 \cdot 013$ & $1 \cdot 20(1 \cdot 07-1 \cdot 35)$ & $0 \cdot 0025$ & $1 \cdot 22(1 \cdot 08-1 \cdot 35)$ & $0 \cdot 0008$ & $1 \cdot 25(1 \cdot 11-1 \cdot 40)$ & $0 \cdot 0001$ & $1 \cdot 14(1 \cdot 04-1 \cdot 24)$ & $0 \cdot 0024$ \\
\hline rs1111875 & HHEX/IDE & $0 \cdot 41$ & $1 \cdot 16(0 \cdot 98-1 \cdot 38)$ & $0 \cdot 104$ & $1 \cdot 21(1 \cdot 07-1 \cdot 37)$ & $0 \cdot 0045$ & $1 \cdot 05(0 \cdot 92-1 \cdot 19)$ & $0 \cdot 51$ & $0 \cdot 94(0 \cdot 84-1 \cdot 06)$ & $0 \cdot 31$ & $1 \cdot 11(1 \cdot 02-1 \cdot 22)$ & $0 \cdot 023$ \\
\hline rs7607980 & COBL1 & $0 \cdot 13$ & $1 \cdot 12(0 \cdot 87-1 \cdot 45)$ & $0 \cdot 32$ & $1 \cdot 12(0 \cdot 93-1 \cdot 34)$ & $0 \cdot 21$ & $1 \cdot 32(1 \cdot 07-1 \cdot 61)$ & $0 \cdot 0044$ & $0 \cdot 99(0 \cdot 83-1 \cdot 17)$ & 0.98 & $1 \cdot 21(1 \cdot 06-1 \cdot 39)$ & $0 \cdot 0027$ \\
\hline rs7647305 & SFRS10 & $0 \cdot 19$ & $0 \cdot 85(0 \cdot 68-1 \cdot 07)$ & $0 \cdot 13$ & $0 \cdot 95(0 \cdot 81-1 \cdot 11)$ & $0 \cdot 38$ & $0 \cdot 80(0 \cdot 68-0 \cdot 95)$ & $0 \cdot 0063$ & $0 \cdot 93(0 \cdot 79-1 \cdot 08)$ & $0 \cdot 26$ & $0 \cdot 92(0 \cdot 82-1 \cdot 03)$ & $0 \cdot 098$ \\
\hline rs5219 & KCNJ11 & $0 \cdot 38$ & $1 \cdot 05(0 \cdot 88-1 \cdot 25)$ & $0 \cdot 61$ & $1 \cdot 18(1 \cdot 04-1 \cdot 34)$ & $0 \cdot 012$ & $1 \cdot 03(0 \cdot 90-1 \cdot 18)$ & $0 \cdot 67$ & $1 \cdot 28(1 \cdot 13-1 \cdot 44)$ & $0 \cdot 00012$ & $1 \cdot 10(1 \cdot 01-1 \cdot 21)$ & $0 \cdot 032$ \\
\hline rs864745 & JAZF1 & $0 \cdot 49$ & $1 \cdot 06(0 \cdot 90-1 \cdot 25)$ & 0.61 & $0 \cdot 91(0 \cdot 80-1 \cdot 02)$ & $0 \cdot 067$ & $0 \cdot 93(0 \cdot 82-1 \cdot 05)$ & $0 \cdot 14$ & $0 \cdot 81(0 \cdot 72-0 \cdot 91)$ & $0 \cdot 00018$ & $0 \cdot 94(0 \cdot 87-1 \cdot 03)$ & $0 \cdot 14$ \\
\hline rs7202877 & BCAR1 & $0 \cdot 12$ & $0 \cdot 89(0 \cdot 70-1 \cdot 14)$ & $0 \cdot 28$ & $1 \cdot 29(1 \cdot 06-1 \cdot 57)$ & 0.029 & $1 \cdot 08(0 \cdot 89-1 \cdot 31)$ & 0.59 & $1 \cdot 35(1 \cdot 11-1 \cdot 64)$ & $0 \cdot 0037$ & $1 \cdot 11(0 \cdot 97-1 \cdot 27)$ & $0 \cdot 17$ \\
\hline rs11708067 & ADCY5 & $0 \cdot 24$ & $0 \cdot 92(0 \cdot 75-1 \cdot 13)$ & $0 \cdot 44$ & $0 \cdot 86(0 \cdot 74-1 \cdot 00)$ & $0 \cdot 052$ & $0 \cdot 86(0 \cdot 73-1 \cdot 00)$ & $0 \cdot 044$ & $0 \cdot 86(0 \cdot 75-0 \cdot 99)$ & $0 \cdot 033$ & $0 \cdot 79(0 \cdot 71-0 \cdot 88)$ & $1.5 \times 10^{-5}$ \\
\hline rs516946 & ANK1 & $0 \cdot 22$ & $0 \cdot 98(0 \cdot 81-1 \cdot 20)$ & $0 \cdot 86$ & $1 \cdot 18(1 \cdot 02-1 \cdot 37)$ & $0 \cdot 031$ & $1 \cdot 13(0 \cdot 97-1 \cdot 32)$ & 0.093 & $1 \cdot 03(0 \cdot 90-1 \cdot 18)$ & 0.61 & $1 \cdot 21(1 \cdot 08-1 \cdot 34)$ & $0 \cdot 00042$ \\
\hline rs243021 & BCL11A & $0 \cdot 47$ & $1 \cdot 05(0 \cdot 89-1 \cdot 24)$ & $0 \cdot 48$ & $1 \cdot 04(0 \cdot 93-1 \cdot 18)$ & $0 \cdot 30$ & $1 \cdot 05(0 \cdot 92-1 \cdot 19)$ & $0 \cdot 45$ & $1 \cdot 04(0 \cdot 92-1 \cdot 16)$ & $0 \cdot 47$ & $1 \cdot 14(1 \cdot 05-1 \cdot 24)$ & $0 \cdot 0026$ \\
\hline rs11063069 & CCND2 & $0 \cdot 20$ & $0 \cdot 83(0 \cdot 66-1 \cdot 04)$ & $0 \cdot 11$ & $1 \cdot 17(1 \cdot 01-1 \cdot 36)$ & $0 \cdot 022$ & $1 \cdot 11(0 \cdot 94-1 \cdot 30)$ & $0 \cdot 16$ & $1 \cdot 11(0 \cdot 96-1 \cdot 29)$ & $0 \cdot 15$ & $1 \cdot 15(1 \cdot 03-1 \cdot 28)$ & $0 \cdot 0084$ \\
\hline rs340874 & PROX1 & $0 \cdot 46$ & $1 \cdot 05(0 \cdot 89-1 \cdot 24)$ & 0.56 & $1 \cdot 02(0 \cdot 91-1 \cdot 15)$ & 0.64 & $0 \cdot 97(0 \cdot 86-1 \cdot 10)$ & 0.75 & $1 \cdot 04(0 \cdot 92-1 \cdot 17)$ & $0 \cdot 47$ & $1 \cdot 12(1 \cdot 03-1 \cdot 22)$ & $0 \cdot 0084$ \\
\hline
\end{tabular}

Maximum likelihood estimation using geographically matched non-diabetic controls $(\mathrm{N}=2754)$. 